\title{
TAFI deficiency causes maladaptive vascular remodeling after hemophilic joint bleeding
}

Tine Wyseure, ${ }^{1}$ Tingyi Yang, ${ }^{1}$ Jenny Y. Zhou, ${ }^{2}$ Esther J. Cooke, ${ }^{1,2}$ Bettina Wanko, ${ }^{3,4,5}$ Merissa Olmer, ${ }^{1}$ Ruchi Agashe, ${ }^{1}$ Yosuke Morodomi, ${ }^{1}$ Niels Behrendt, ${ }^{6}$ Martin Lotz, ${ }^{1}$ John Morser, ${ }^{3}$ Annette von Drygalski ${ }^{1,2}$ and Laurent O. Mosnier

'Deptartment of Molecular Medicine, The Scripps Research Institute, La Jolla, California, USA. ²Department of Medicine, UCSD, San Diego, California, USA. ${ }^{3}$ Division of Hematology, Department of Medicine, Stanford University School of Medicine, Stanford, California, USA. ${ }^{4}$ Veterans Affairs Palo Alto Health Care System, Palo Alto, California, USA. ${ }^{5}$ Clinical Division of Endocrinology and Metabolism, Department of Medicine III, Medical University Vienna, Vienna, Austria. ${ }^{6}$ The Finsen Laboratory, Rigshospitalet/Biotech Research and Innovation Centre (BRIC), University of Copenhagen, Copenhagen, Denmark.

Excessive vascular remodeling is characteristic of hemophilic arthropathy (HA) and may contribute to joint bleeding and the progression of HA. Mechanisms for pathological vascular remodeling after hemophilic joint bleeding are unknown. In hemophilia, activation of thrombin-activatable fibrinolysis inhibitor (TAFI) is impaired, which contributes to joint bleeding and may also underlie the aberrant vascular remodeling. Here, hemophilia A (factor VIII-deficient; FVIII-deficient) mice or TAFI-deficient mice with transient (antibody-induced) hemophilia A were used to determine the role of FVIII and TAFI in vascular remodeling after joint bleeding. Excessive vascular remodeling and vessel enlargement persisted in FVIII-deficient and TAFI-deficient mice, but not in transient hemophilia WT mice, after similar joint bleeding. TAFI-overexpression in FVIII-deficient mice prevented abnormal vessel enlargement and vascular leakage. Age-related vascular changes were observed with FVIII or TAFI deficiency and correlated positively with bleeding severity after injury, supporting increased vascularity as a major contributor to joint bleeding. Antibody-mediated inhibition of uPA also prevented abnormal vascular remodeling, suggesting that TAFI's protective effects include inhibition of uPA-mediated plasminogen activation. In conclusion, the functional TAFI deficiency in hemophilia drives maladaptive vascular remodeling in the joints after bleeding. These mechanistic insights allow targeted development of potentially new strategies to normalize vascularity and control rebleeding in HA.

Conflict of interest: AVD has received honoraria for participating in scientific advisory board panels, consulting, and speaking engagements for Baxalta/ Shire, Bayer, Pfizer, Bioverativ, CSLBehring, and Novo Nordisk.

Copyright: (c) 2019, American Society for Clinical Investigation.

Submitted: March 25, 2019

Accepted: August 23, 2019

Published: October 3, 2019

Reference information: JCI Insight. 2019;4(19):e128379.

https://doi.org/10.1172/jci.

insight.128379.

\section{Introduction}

Hemophilia A and B are inherited bleeding disorders due to a X-linked genetic deficiency in clotting factor VIII (FVIII) or FIX, respectively. Patients with severe hemophilia (factor levels $<1 \%$ ) experience frequent joint bleeds starting at an early age when not controlled with prophylactic clotting factor replacement therapy (1-3). The frequent exposure of the joint to blood causes the development of hemophilic arthropathy (HA), a debilitating and irreversible condition that often requires joint replacements at early ages (4). Today's focus on managing acute bleeds in hemophilia and optimizing prophylactic treatment has significantly reduced the number of life-threatening bleeds and delayed the early onset of HA (1). However, HA continues to develop later in life, despite prophylaxis, suggesting that breakthrough and/or subclinical bleeding in the joints induce pathological soft tissue and osteochondral changes that accumulate over time, causing joint deformities and HA (5-7). Indeed, a few bleeds in rapid succession suffice to form target joints (i.e., joints with a predisposition to chronic synovial inflammation, persistent bleeding, and at high risk of developing HA; ref. 8). The etiology of target joint formation and persistent joint bleeding despite clotting factor treatment is multifaceted, as is the pathology of HA, and remains incompletely understood (4).

One distinctive pathophysiological manifestation of hemophilic joints associated with bleeding is the induction of excessive and abnormal vascular remodeling (9). Featuring progressive vascular wall remodeling 
with vessel lumen enlargement, these enlarged, tortuous vessels in HA appear fragile and prone to rupture, as shown by ample clinical evidence (10-14). Furthermore, association of high synovial power Doppler (PD) signals, a measure of abnormal microvascular flow and increased vascularity, with subclinical or overt joint bleeding in adult patients with hemophilia support the link between vascular changes in the joint and susceptibility to bleeding $(9,11,15)$. Normal synovium contains a dense network of fenestrated blood microvessels but is relatively devoid of larger vasculature. It is conceivable that the presence of enlarged and possibly dysfunctional synovial vascularity contributes to joint bleeding in hemophilia, which in some cases cannot be controlled by clotting factor replacement alone, requiring surgical intervention to embolize the vessels and stop the bleeding $(10,14,16-18)$.

The driving forces for the abnormal growth of these blood vessels and pathogenic vascular remodeling are largely undefined. Neovascularization after joint bleeding is induced by the combination of hypoxia due to synovial hyperproliferation and the expression of proto-oncogenes and proinflammatory cytokines in response to exposure of the synovium to toxic hemoglobin-derived iron and iron derivatives $(4,19-22)$. Why this neovascular response results in pathogenic vascular remodeling in hemophilia remains undetermined. Excessive vascular remodeling is characteristic of HA, as it is not observed to the same extent in rheumatoid and osteo-arthritis $(9,11)$. The less conspicuous vascular remodeling in the other arthritides indicates that mechanisms other than inflammation- and/or degeneration-driven processes are involved in the aberrant hypervascular response in HA, and that most likely the underlying FVIII or FIX deficiency is driving the excessive vascular remodeling. The major consequence of FVIII or FIX deficiency is severely impaired thrombin generation, which affects multiple pathways beyond hemostasis.

One important protein, potentially affecting vascular remodeling in the hemophilic joint, is thrombin-activatable fibrinolysis inhibitor (TAFI, also known as procarboxypeptidase U or plasma procarboxypeptidase $\mathrm{B}$, gene $C P B 2$ ). TAFI is a circulating proenzyme activated by thrombin or the thrombin-thrombomodulin complex $(23,24)$, and the activation of TAFI is particularly impaired in hemophilia, as shown in hemophilia plasma in vitro (25-27) and in FVIII-gene deficient (FVIII-KO) mice after joint injury in vivo (28). Activated TAFI (TAFIa) is a basic carboxypeptidase that removes C-terminal Lys or Arg from specific proteins and peptides, resulting generally in their attenuated bioactivity $(29,30)$. Loss of TAFIa activity in hemophilia was recently found to promote joint bleeding due to unopposed uPA-mediated activation of plasminogen (28), which is normally attenuated by TAFIa due to the removal of C-terminal Lys from partially degraded fibrin $(31,32)$. In addition, TAFIa has antiangiogenic effects on endothelial cells (33), reduces migration and invasion of breast cancer cells $(34,35)$, and attenuates the formation of abdominal aorta aneurysms in vivo (36), which was ascribed to its ability to reduce extracellular matrix degradation by suppressing plasmin formation. TAFIa also provides protective antiinflammatory effects in various mouse models of arthritis by reducing synovitis and cartilage destruction, and this primarily involves inactivation of the complement anaphylatoxins C3a and C5a, and of thrombin-cleaved osteopontin by removal of their C-terminal Arg (37-40).

Thus, based on the defective activation of TAFI in hemophilia that contributes to joint bleeding and TAFI's protective effects in other arthritis models, we hypothesize that the loss of TAFIa activity in hemophilia provides a disease-promoting role in HA by augmenting the excessive vascular remodeling, thereby posing a serious risk for recurrent joint bleeding and development of HA. Here, we used WT and TAFIKO mice with transient (antibody-induced) hemophilia A and congenital hemophilia A (FVIII-KO) mice to discern normal from abnormal long-term vascular changes in response to joint bleeding. This approach permits the identification of how FVIII deficiency gives rise to the abnormal vascular responses after joint bleeding in hemophilia.

\section{Results}

Extensive vascular abnormalities are present in the synovium of patients with $H A$. The synovial vascularity of normal human knee joints is characterized by small CD $31^{+}$vessels in the sublining layer adjacent to the synovial layer (Figure 1, A-C) that provides nutrients to the synovial fluid and avascular cartilage. Synovium from patients with HA is hyperplastic and has very different synovial vascularity, with a high density of abnormally enlarged blood vessels with distorted vascular walls throughout the different synovial layers (Figure 1, D-F). A significant subset of the abnormally enlarged $\mathrm{CD} 31^{+}$vessels showed excessive perivascular cell staining for $\alpha$-smooth muscle actin ( $\alpha \mathrm{SMA}$ ) (Figure 1, D-F), indicative of a maladaptive vascular remodeling response (9). While total vessel count (Figure $1 G$ ) and average vessel diameter (Figure $1 \mathrm{H}$ ) were similar in HA samples compared with normal controls, the vessel count of abnormally enlarged vessels with a vessel 
A
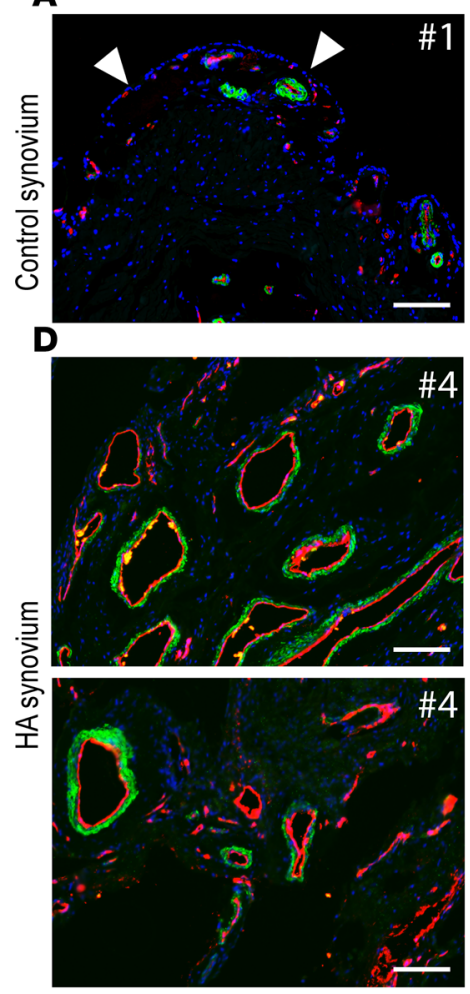

B
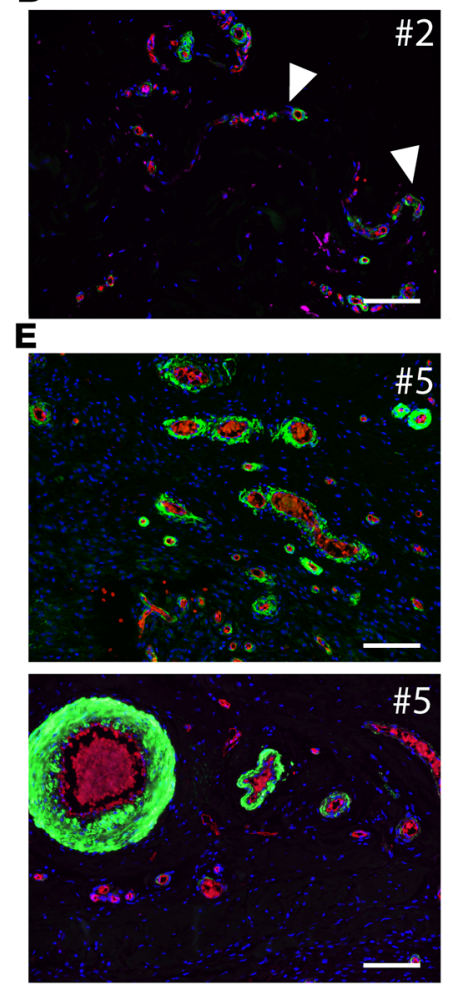

C
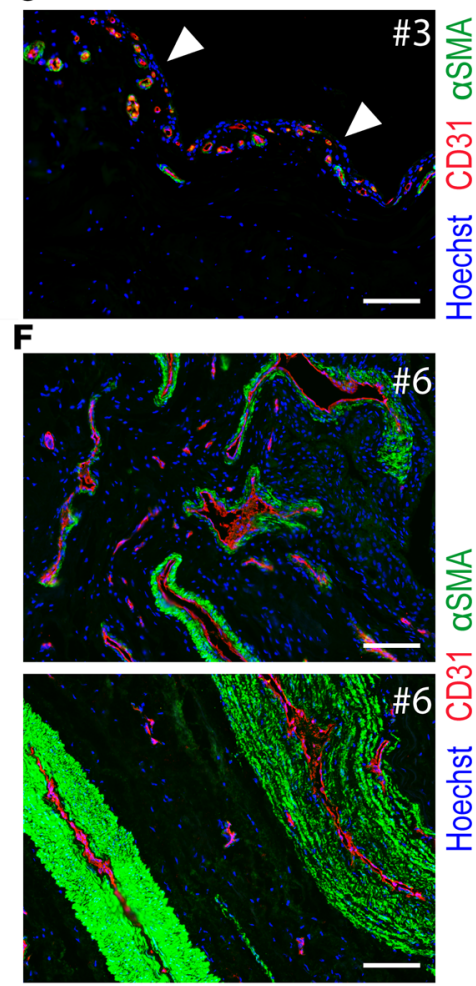

G

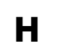

I

J

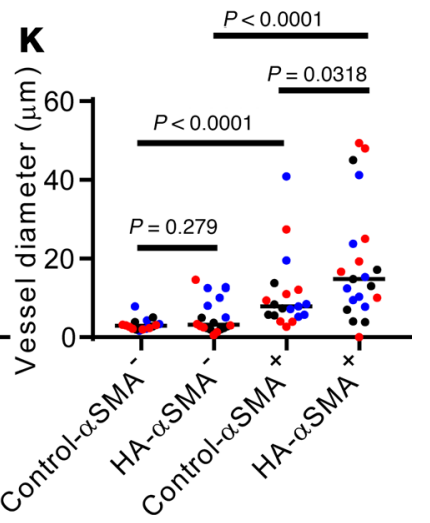

Figure 1. Vascular changes in synovial samples from hemophilia patients with HA. Representative images of synovial samples from 3 normal control donors (numbered 1-3; A-C) and from 3 hemophilia patients with HA (numbered 4-6; 2 examples each; D-F) stained for CD31 (red), $\alpha$ SMA (green), and nuclei (Hoechst, blue). Arrowheads indicate synovial surface typically comprising 2-3 cell layers in control samples with a high density of small CD31+ $\alpha S^{+} \mathrm{A}^{-}$ and $\mathrm{CD} 1^{+} \alpha \mathrm{SMA}^{+}$vessels in the sublining. In $\mathrm{HA}$ synovial samples, abnormally enlarged vessels reside in multiple synovial layers with excessive ( $\left.\alpha \mathrm{SMA}^{+}\right)$ perivascular remodeling. Original magnification 20x. Scale bar: $100 \mu \mathrm{m}$. (G-K) Quantification of 5-7 high-power fields (HPF) per donor and 3 donors per condition (median; counts derived from different HPF of the same donor are color coded blue, black, and red). (C) Total vessel count, (H) average vessel diameter $(\mu \mathrm{m})$, (I) vessel count with diameter $\geq 20 \mu \mathrm{m}$, (J) vessel count with diameter $\geq 40 \mu \mathrm{m}$, and (K) average vessel diameter ( $\mu \mathrm{m})$ of CD31+ $\alpha \mathrm{SMA}^{-}$and CD31+ $\alpha \mathrm{SMA}^{+}$count of vessels per HPF. Data were analyzed using 2-tailed, unpaired Mann-Whitney $U$ test (G-K).

lumen diameter $\geq 20 \mu \mathrm{m}$ (Figure 1I) or $\geq 40 \mu \mathrm{m}$ (Figure $1 \mathrm{~J}$ ) and average diameter of $\alpha \mathrm{SMA}^{+}$, but not $\alpha \mathrm{SMA}^{-}$, blood vessels (Figure $1 \mathrm{~K}$ ) were significantly increased in HA samples, indicating that the vessel enlargement and vascular wall remodeling are characteristic of HA. The needle puncture-induced knee injury model in FVIII-KO mice was established to capture these characteristic vascular changes of HA and permits different time-dependent intraarticular soft tissue processes caused by bleeding to be distinguished (Supplemental Figure 1 and ref. 28; supplemental material available online with this article; https://doi.org/10.1172/jci. insight.128379DS1). To discriminate normal (WT) responses to joint bleeding from abnormal responses that are caused by FVIII deficiency, these different processes are defined here as bleeding, synovial inflammation 
A

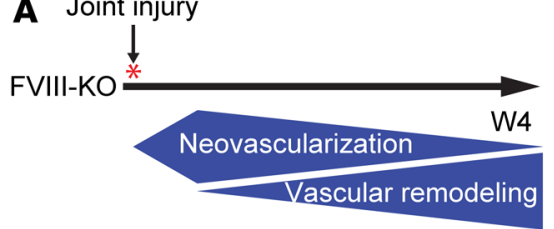

B Anti-FVIII antibody : WT ${ }^{\mathrm{NN}}$

Anti-FVIII + Anti-TAFI antibody : WT ${ }^{T N H+}$

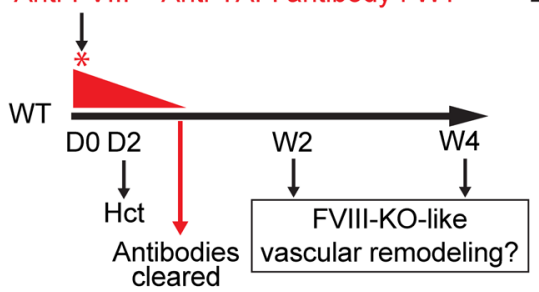

C

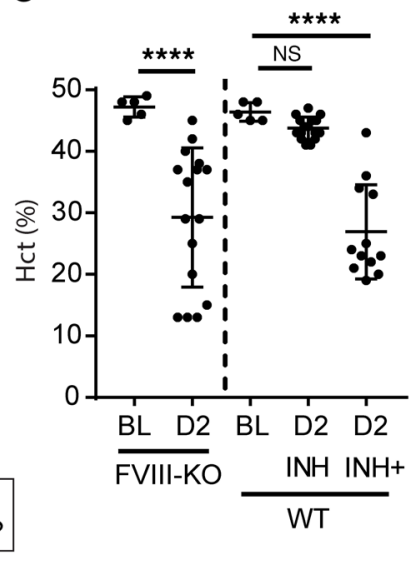

E
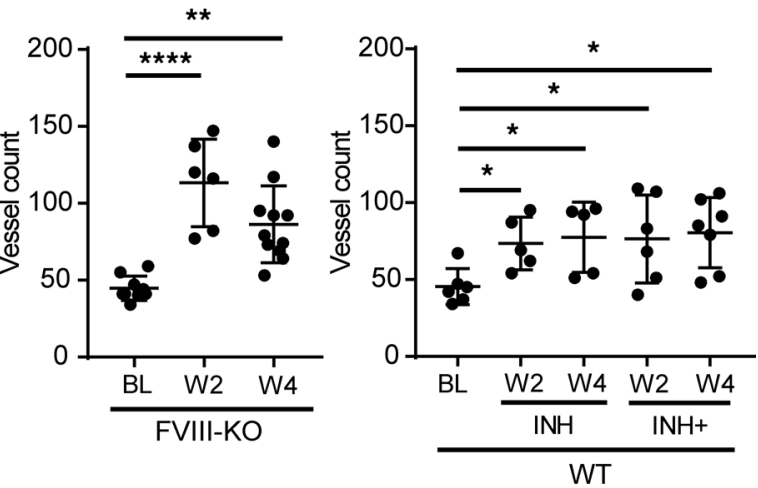

I
D

H

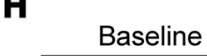

OBaseline

W4
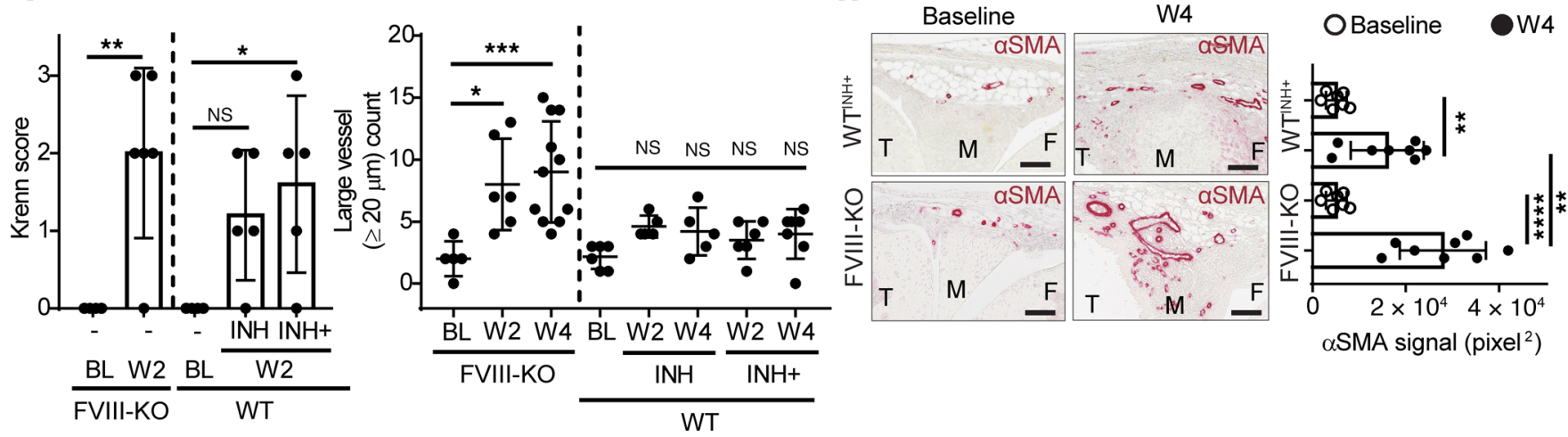

Figure 2. WT mice with transient hemophilia A are protected against excessive vascular remodeling after joint bleeding. (A) Schematic of an established joint injury model and bleeding-induced vascular changes in BALB/C FVIII-KO mice (9) with synovial neovascularization normalizing gradually, while vascular remodeling into enlarged and distorted vessels progresses. (B) Schematic of the joint injury model in WT mice with transient hemophilia A. BALB/c WT mice were administered an inhibitory anti-FVIII antibody alone (WT-inhibitor; WT ${ }^{\text {NHH) }}$ ) or together with an anti-TAFI antibody (WT-inhibitor plus; $\mathrm{WT}^{\mathrm{INH}+}$ ). After antibody clearance, vascular changes in WT mice were compared at week 2 (W2) and W4 with those in FVIII-KO mice. Asterisk indicates time of joint injury at day 0 (DO). Hematocrit (Hct) was determined at D2 after injury to assess joint bleeding severity. (C) Hct at baseline (BL; $n=$ 5) and D2 in FVIII-KO, W $T^{\mathrm{INH}}$, or W $\mathrm{T}^{\mathrm{INH}+}$ mice $(n=12-16)$. Joint bleeding was inferred from a postinjury Hct drop. ( $\mathbf{D}$ and $\left.\mathbf{E}\right)$ Total vessel count in medial knee joint sections at baseline and after knee injury in FVIII-KO mice $(n=6-11)(\mathbf{D})$, WT ${ }^{\mathrm{INH}}$ mice $(\mathbf{E})$, and WT ${ }^{\mathrm{INH}+}$ mice $(n=5-7)(\mathbf{E})$. (F) Synovial proliferation $(\mathrm{Krenn}$

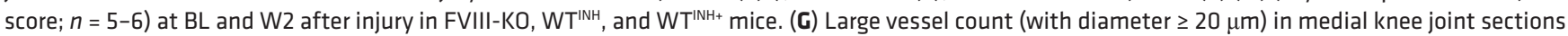
at $\mathrm{BL}, \mathrm{W} 2$, and $\mathrm{W} 4$ after injury in FVIII-KO, WT ${ }^{\mathrm{INH}}$, and $\mathrm{WT}^{\mathrm{INH}+}$ mice $(n=5-11)$. (H) Representative examples of $\alpha \mathrm{SMA}$ staining. Scale bar: $100 \mu \mathrm{m}$. T, tibia; $\mathrm{M}$, meniscus; F, femur. (I) Quantification of the $\alpha$ SMA signal $(n=7-8)$ in WT ${ }^{I N H+}$ or FVIII-KO mice at BL and at W4 after injury. Each point represents an individual mouse. Data are presented as mean \pm SD and were analyzed using 1-way ANOVA with Tukey's multiple comparisons test (C, D, G, and I), Kruskal-Wallis with Dunn's multiple comparisons test (F) or Student's 2-tailed, unpaired $t$ test $(\mathbf{E}) .{ }^{*} P<0.05 ;{ }^{* *} P<0.01 ;{ }^{* *} P<0.001 ;{ }^{* * *} P<0.0001$.

and hyperplasia, neovascularization, and vascular remodeling. While HA in humans progresses as the result of many joint bleeds over time, the FVIII-KO mouse mimics the human joint histopathological changes after a single severe joint bleed with regard to maladaptive vascular remodeling (Supplemental Figure 2).

WT mice with transient hemophilia $A$ display synovial hyperplasia and neovascularization after joint bleeding. FVIII-KO (Figure 2A) and WT control mice (Figure 2B) were used to study the driving forces responsible for the excessive vascular remodeling in hemophilia after joint bleeding. Injury-induced joint bleeding in WT mice was achieved by transient antibody-mediated inhibition of FVIII alone, which induced less than hemophilia-like bleeding volumes, or by the inhibition of both FVIII and TAFI to induce hemophilia-like bleeding volumes (Figure 2B and ref. 28). Antibody-induced abrogation of hemostasis was transient due to clearances of the antibodies in $<5$ days (anti-FVIII [ref. 28]; anti-TAFI, Supplemental Figure 3) and permitted the assessment of the effects of bleeding volume and the presence of FVIII during different stages after injury on vascular changes in the joint. The FVIII-KO mouse on the BALB/c genetic background does not bleed spontaneously (41, 42); accordingly, hematocrit (Hct) (Figure 2C) and joint vascularity at baseline were similar to those observed in WT mice (total vessel count of $42 \pm 3$ in FVIII-KO mice versus $43 \pm 9$ in WT mice; Figure 2, D and E), indicating that FVIII deficiency does not induce developmental 
or spontaneous vascular abnormalities in these mice. After joint injury in the FVIII-KO mouse, excessive bleeding - as shown by a marked drop in Hct at day 2 (D2) after injury (Figure 2C) - caused the formation of an intra- and periarticular hematoma (Supplemental Figure 1). Joint bleeding in the FVIII-KO mouse induced synovial hyperplasia (Figure 2F) and excessive neovascularization (Figure 2D) that was more pronounced at week 2 (W2) than W4. WT mice subjected to transient hemophilia A by injection of an inhibitory anti-FVIII antibody (WT mouse with inhibitor, $\mathrm{WT}^{\mathrm{INH}}$; Figure $2 \mathrm{~B}$ ) developed moderate synovial hyperplasia (Figure 2F) and neovascularization (Figure 2E) at W2 and W4, although only minimal joint bleeding was observed in the presence of the anti-FVIII antibody (some bleeding did occur [ref. 28] but not sufficient to induce a decreased D2 Hct) (Figure 2C). In contrast, WT mice without injection of the anti-FVIII antibody subjected to a joint injury did not bleed and did not develop neovascularization or soft tissue hyperplasia (Supplemental Figure 4). Therefore, synovial hyperplasia and the neovascular response develop in WT mice with transient hemophilia A at very small bleeding volumes that are not seen in hemostatically competent WT mice after injury.

$W T$ mice with transient hemophilia $A$ are protected against excessive vascular remodeling after joint bleeding. The distinctive feature of the vascular changes in hemophilia after joint bleeding is the aberrant vascular remodeling that is characterized by the formation of large, irregularly-shaped vessels often (partially) covered by a thick layer of $\alpha \mathrm{SMA}^{+}$pericytes and vascular smooth muscle cells (Figure 1). However, WT ${ }^{\mathrm{INH}}$ mice did not show a significant increase in abnormally large blood vessels $(\geq 20 \mu \mathrm{m})$ that is typically observed in the FVIII-KO mice at W2 or W4 (Figure 2G). The minimal joint bleeding in WT ${ }^{\mathrm{INH}}$ mice is due to residual activation of TAFI (28). When WT mice were administered an inhibitory anti-TAFI antibody, MA-RT36A3F5, in combination with the anti-FVIII antibody (WT mouse with anti-FVIII plus anti-TAFI inhibitor, WT ${ }^{\mathrm{INH}^{+} \text {; }}$ Figure 2B), joint bleeding was quantitatively similar to FVIII-KO mice (Hct at D2, $24.5 \% \pm 7 \%$ for $\mathrm{WT}^{\mathrm{INH}^{+}}$ mice versus $26.5 \% \pm 9 \%$ for FVIII-KO mice; Figure $2 \mathrm{C}$ ). Similar joint vascularity patterns were observed in $\mathrm{WT}^{\mathrm{INH}}$ and $\mathrm{WT}^{\mathrm{INH}+}$ mice after injury, independently of the different joint bleed volumes (Figure 2, E and G). Moreover, exposure to blood in the WT joints resulted in an inflammatory and angiogenic response, as shown by soft tissue hyperplasia (Figure $2 \mathrm{~F}$ and Supplemental Figure 5) and an increased total vessel count at W2 (Figure 2F), although to a lesser extent than observed in FVIII-KO mice. In stark contrast to FVIII$\mathrm{KO}$ mice, $\mathrm{WT}^{\mathrm{INH}+}$ mice did not develop such enlarged vascular structures (Figure 2G and Supplemental Figure 6), despite their similar joint bleed volumes. Although $\mathrm{WT}^{\mathrm{INH}+}$ mice showed an increase in the number of $\alpha \mathrm{SMA}^{+}$smaller vessels, the large irregularly shaped $\alpha \mathrm{SMA}^{+}$vessels typical in FVIII-KO mice were notably diminished (Figure 2, H and I). Thus, abnormal vessel enlargement and vascular remodeling were almost absent in WT $\mathrm{T}^{\mathrm{INH}+}$ mice and present with FVIII deficiency, defining a prominent role of FVIII and/or FVIII-dependent downstream factors beyond initial hemostasis to arrest bleeding.

TAFI deficiency results in spontaneously increased joint vascularity with aging. Ultrasound $\mathrm{PD}$ has been validated to measure aberrantly increased blood flow in response to joint bleeding in patients with hemophilia $(9,11)$. In FVIII-KO mice, PD signals increase after joint injury (Supplemental Figure 7) and correlate with vessel diameter $(9,15,43)$. To test our hypothesis that TAFI deficiency may be the underlying cause of the prolonged vascular dysfunction in hemophilia after bleeding, the joint vascularity of uninjured TAFI-KO mice was characterized by PD. At baseline, a subset of skeletally mature TAFI-KO mice (3-4 months of age) exhibited spontaneously increased PD signals when compared with age-matched WT control mice (Figure 3, A and B). In contrast, FVIII-KO mice had normal PD signals at baseline (Figure 3, A and B) that corresponded to their intrinsically low baseline vascularity shown by histology (Figure 2, D and G). Because HA is most common in the adult hemophilia population, an aging study was conducted in mice to better understand the effects of TAFI and FVIII deficiency on age-related spontaneous changes in joint vascularity (Figure 3A). In general, the joint vascularity, measured by PD imaging, increased with aging in WT controls (C57B1/6J [TAFI-KO background] and BALB/c [FVIII-KO background]) and plateaued at 8-10 months of age (Figure 3B). PD signals also increased with age in FVIII-KO mice, but in contrast to WT mice, PD signals did not plateau at 8-10 months, continuing to increase with age (Figure 3B) and showing a greater abundance of high-flow areas at 18 months (Figure 3C). In TAFI-KO mice, PD signals were increased in all age groups (3, 9, and 18 months), showing markedly altered vascularity patterns (Figure 3D), reminiscent of those seen in FVIII-KO mice after severe joint bleeding. To exclude the possibility that the increased PD signals in this TAFI-KO line (44) were due to potential off-target effects as the result of genetic drift, results were confirmed in an independently generated and maintained TAFI-KO strain (45). Indeed, increased PD signals were also observed in this TAFI-KO line in both younger ( $<6$ months) and aged ( $>6$ months) mice 

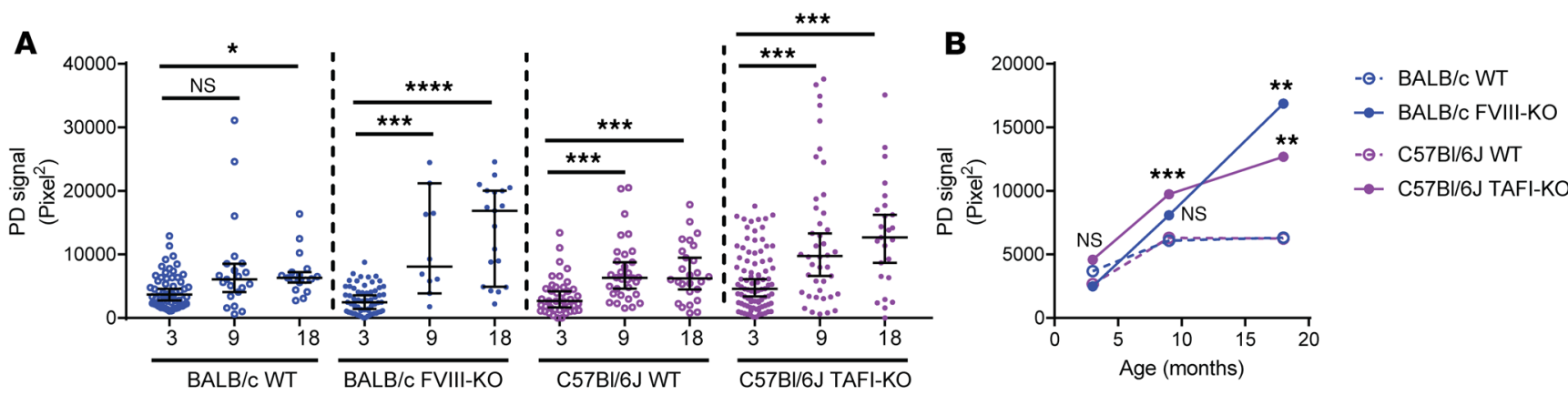

C

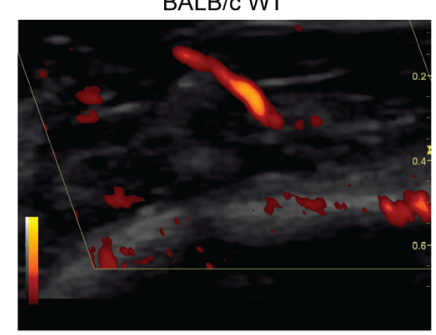

BALB/C FVIII-KO

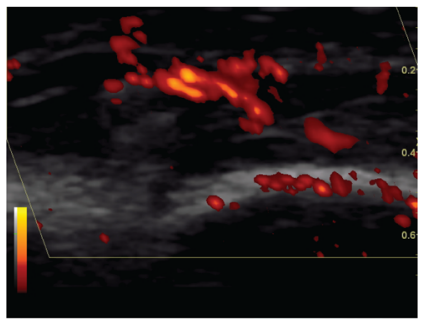

D

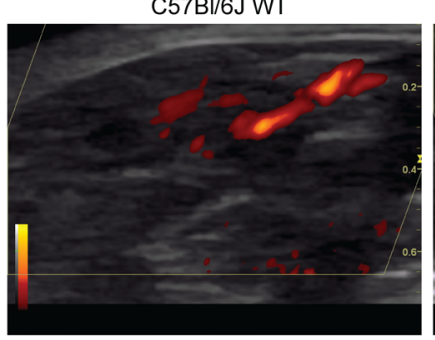

C57BI/6J TAFI-KO

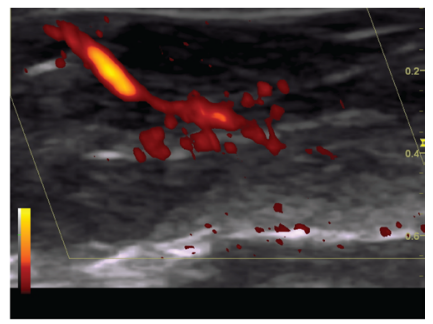

Figure 3. Joint blood flow increases spontaneously with aging in TAFI-deficient mice. (A) Analysis of knee joint vascularity at baseline (no injury) by ultrasound power Doppler (PD) (pixel'; median $\pm 95 \% \mathrm{CI}$ ) in BALB/c WT ( $n=17-58)$, BALB/c FVIII-KO ( $n=10-61)$, C57BI/6J WT ( $n=26-41)$, and C57BI/6) TAFI-KO ( $n=25-89$ ) mice at 3-4 months ("3"), 8-10 month ("9"), and 18-22 months ("18") of age. PD signal was obtained from recording at the medial side of the right knee joint. Each point represents an individual mouse. (B) Analysis of age-related increases in PD signal (pixel2; median) in joints of BALB/c FVIII-KO mice $(n=10-61)$ and C57BI/6) TAFI-KO $(n=25-89)$ compared with their respective age-matched WT controls $(n=17-58$ for BALB/c WT and $n=26-41$ for [57BI/6] WT) at 3-4 months ("3"), 8-10 month ("9"), and 18-22 months ("18"). Statistical significance is shown versus age-matched WT control mice. (C and D) Representative images of PD recordings at $>18$ months for (C) BALB/C FVIII-KO mice and (D) C57BI/6J TAFI-KO and their respective age-matched WT controls. The intensity of vascular flow is pseudocolored from low flow (red) to high flow (yellow) as indicated. Original scaled dimensions are $0.86 \mathrm{~cm}$ (w) $\times 0.63 \mathrm{~cm}$ (h). Data were analyzed using Kruskal-Wallis with Dunn's multiple comparisons test. ${ }^{*} P<0.05 ;{ }^{* *} P<0.01 ;{ }^{* * *} P<0.001 ;{ }^{* * * *} P<0.0001$.

compared with their respective age-matched WT controls (Supplemental Figure 8). Histological analysis at 18 months showed an overall increase in joint vascularity in TAFI-KO mice (Figure 4). Vessel count (Figure 4A) and average diameter (Figure 4B) were higher in 18-month-old TAFI-KO mice. However, vessel enlargement expressed as vessel count with a diameter $\geq 40 \mu \mathrm{m}$ (Figure $4 \mathrm{C}$ ), and perivascular $\alpha$ SMA signals (Figure 4, D and E) were significantly increased in both aged TAFI-KO and FVIII-KO mice, indicating enhanced vascular remodeling with aging in these mice and confirming increased vascularity and vessel lumen expansion as the cause for the increased PD signals. The augmented age-dependent vessel enlargement in TAFI-KO mice uncovered a potentially novel physiological role for TAFI in the regulation of vascularity in weight-bearing joints and extends its protective role in arthritis $(39,40)$. Furthermore, phenocopying of the hemophilia-related spontaneous vascular changes in the TAFI-KO mouse provides support for our hypothesis that defective TAFI activation in hemophilia is responsible for abnormal vascular remodeling.

Maladaptive vascular remodeling with aging increases joint bleeding. Although the link between abnormal vascular remodeling in the joint and susceptibility to joint bleeding in hemophilia is intuitive and based on ample clinical experience (9-15), direct experimental evidence is currently lacking. When a very mild joint injury was induced in transient hemophilia A TAFI-KO mice (TAFI-KO ${ }^{\mathrm{INH}}$ ) at 8 months of age that displayed a wide range of PD signals, a significant correlation was observed between the bleeding severity after joint injury and PD signals at baseline before injury (Figure 5A). Stratifying the aged TAFI-KO mice based on PD signal at baseline indicated that mice with high PD signals bled significantly more after a very mild joint injury compared with mice with normal PD signals (Figure 5B). Thus, mice with increased vascular blood flow in the joint are predisposed to more severe joint bleeding, providing experimental support for the clinical experience that dysfunctional vascular remodeling is a major contributor to joint bleeding in hemophilia patients.

TAFI deficiency phenocopies the vascular dysfunction in FVIII-KO mice after joint bleeding. To test whether TAFI deficiency causes FVIII-KO-like vascular remodeling after joint bleeding, TAFI-KO mice with a normal baseline PD signal (less than the mean plus $1 \times$ SD) of the baseline PD signal in WT mouse; Supplemental Figure 9) were subjected to joint bleeding. Administration of the anti-FVIII antibody (and anti-TAFI antibody) prior to 

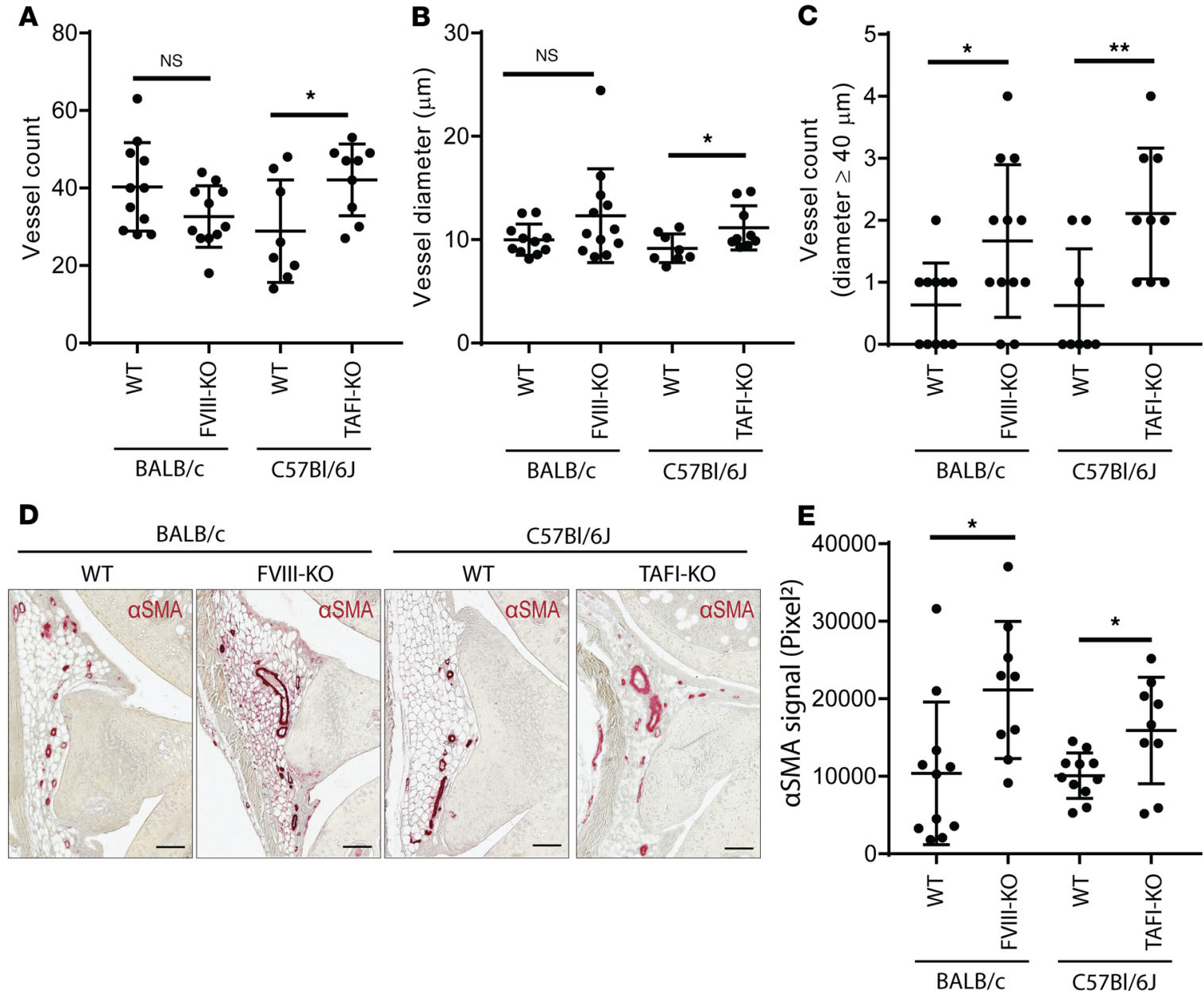

Figure 4. Joint vascularity is increased in aged TAFI-KO mice. Analysis of joint vascularity at baseline (no injury) based on histology of Safranin 0 fast Green-stained sections of BALB/C WT, BALB/C FVIII-KO, C57BI/6J WT, and C57BI/6J TAFI-KO mice at 18-22 months of age. Mice with a PD signal between the mean \pm SD (Figure 3) were selected for histological examination. Each point represents an individual mouse $(n=8-12)$. (A) Total vessel count, (B) average vessel diameter, (C) vessel count with diameter $\geq 40 \mu \mathrm{m}$, and (E) quantification of perivascular $\alpha$ SMA signal (pixel'; $n=9-11$ ) of BALB/C FVIII-KO mice and C57BI/6] TAFI-KO at 18-22 months compared with their respective age-matched WT controls. (D) Representative images of $\alpha$ SMA staining. Original magnification $40 x$. Scale bar: $100 \mu \mathrm{m}$. Data are represented as mean \pm SD and were analyzed using Student's 2-tailed, unpaired $t$ test $(\mathbf{A}-\mathbf{C}$ and $\mathbf{E}) .{ }^{*} P<0.05 ;{ }^{* *} P<0.01$.

joint injury (Figure 6A) ensured FVIII-KO-like bleeding (D2 Hct 26.5\% \pm 9\%; Figure 2C) in TAFI-KO ${ }^{\mathrm{INH}}$ (D2 Hct $25.6 \% \pm 4.6 \%$ ) and $\mathrm{C} 57 \mathrm{Bl} / 6 \mathrm{~J} \mathrm{WT}^{\mathrm{INH}+}$ mice (D2 Hct 29.3\% $\pm 7.8 \%$; Figure $6 \mathrm{~B}$ ). PD signals 4 weeks after injury were increased in TAFI-KO ${ }^{\mathrm{INH}}$ mice (Figure 6C) and showed markedly altered flow patterns (Figure 6D), which were similar to those in FVIII-KO mice after injury (Supplemental Figure 7). PD signals 4 weeks after injury were not significantly increased in $\mathrm{WT}^{\mathrm{INH}+}$ mice compared with preinjury baseline (Figure 6, C and D). This suggests that the increased PD signals are caused by TAFI deficiency after the anti-FVIII antibody (in TAFI-KO ${ }^{\mathrm{INH}}$ and $\mathrm{WT}^{\mathrm{INH}+}$ mice) and the anti-TAFI antibody (in $\mathrm{WT}^{\mathrm{INH}+}$ mice) have cleared from the circulation (D4-D7 after injury, as determined previously for anti-FVIII antibody [ref. 28]; anti-TAFI antibody (Supplemental Figure 3) and that FVIII deficiency at that time is not a prerequisite per se for vascular changes. Histological analysis corroborated the PD findings and confirmed that total vessel count (Figure 7A), average vessel diameter (Figure 7B), and the number of abnormally enlarged ( $\geq 20 \mu \mathrm{m}$ ) vessels (Figure 7C and Supplemental Figure 10) were significantly increased in TAFI-KO ${ }^{\mathrm{INH}}$ mice compared with $\mathrm{WT}^{\mathrm{INH}+}$ mice. Moreover, the number of abnormally enlarged vessels in homozygous TAFI-KO ${ }^{\mathrm{INH}}$ mice was increased compared with that in heterozygous TAFI-KO ${ }^{\mathrm{INH}}$ and $\mathrm{WT}^{\mathrm{INH}+}$ littermate control mice (Supplemental Figure 11). Absolute vessel numbers for vascularity changes in TAFI-KO ${ }^{\mathrm{INH}}$ mice (Figure 7, A-C) were similar to those found in FVIII-KO mice after injury (Figure 2, D and G). TAFI-KO ${ }^{\mathrm{INH}}$ mice also demonstrated significantly increased 

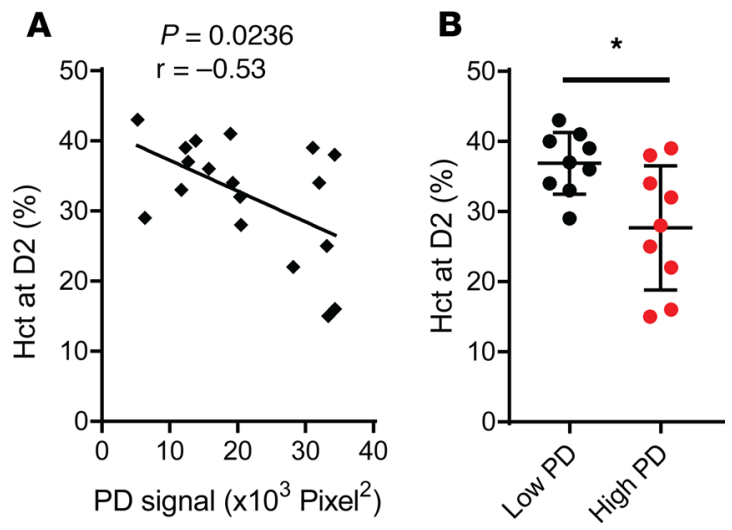

Figure 5. Correlation between joint vascularity and injury-induced bleeding. (A) Correlation of joint vascularity in [57BI/6) TAFI-KO mice (8-10 months old; $n=18$ ), as determined by measuring the ultrasound power Doppler (PD) signal (pixel ${ }^{2}$ ) at baseline versus injury-induced joint bleeding (very mild injury) upon administration of the inhibitory antiFVIII antibody. Joint bleeding is inferred from the hematocrit (Hct; \%) at day 2 (D2) after injury. (B) Hematocrit at D2 (\%; mean \pm SD) after injury of mice with low $(0-50 \% ; n=9)$ versus high $(50-100 \% ; n=9)$ baseline PD signals in C57BI/6) TAFI-KO mice (8-10 months) treated with inhibitory anti-FVIII antibody. Each point represents an individual mouse. Correlation was analyzed using the Pearson correlation test (A), and data were analyzed using Student's 2-tailed, unpaired $t$ test (B). ${ }^{*} P<0.05$.

synovial hyperplasia (Supplemental Figure 12) and perivascular remodeling, as indicated by an increased aSMA signal that was not seen in $\mathrm{C} 57 \mathrm{Bl} / 6 \mathrm{~J} \mathrm{WT}^{\mathrm{INH}+}$ mice (Figure 7, D and E), similar to BALB/c WT ${ }^{\mathrm{INH}+}$ mice (Figure 2, H and I). Thus, transient hemophilia A in WT mice did not phenocopy the abnormal vascular remodeling response after joint bleeding, as observed in FVIII-KO mice, despite similar joint bleeding volumes in the $\mathrm{WT}^{\mathrm{INH}+}$ and FVIII-KO mice. TAFI-KO mice with transient hemophilia A (TAFI-KO ${ }^{\mathrm{INH}}$ ), in contrast, did phenocopy the maladaptive vascular remodeling response of the FVIII-KO mice after joint bleeding, as vascularity determined by histological examination was similar between TAFI-KO ${ }^{\mathrm{INH}}$ mice and FVIII-KO mice.

TAFI deficiency increases vascular permeability after joint bleeding. Increased vascular permeability and edema are key features of endothelial dysfunction caused by inflammation and/or chronic angiogenesis. As previously reported, the vascular permeability of the joint vasculature markedly increases 2 weeks after joint bleeding in the FVIII-KO mouse and normalizes by W4 (15). The increased vascular leakage of Evans blue-albumin in injured joints of TAFI-KO ${ }^{\mathrm{INH}}$ mice was indistinguishable from FVIII-KO mice at W2 when compared with the uninjured contralateral joints (Figure 8A), and the ratio of vascular permeability in injured versus contralateral uninjured joints was significantly increased at W2 compared with no-injury baseline in both mice and returned to baseline by W4 (Figure 8B). WT $\mathrm{T}^{\mathrm{INH}+}$ mice did not show increased vascular permeability at W2 compared with baseline, consistent with the mild neovascularization reaction in these mice, whereas the vascular leakage of Evans blue-albumin was significantly higher in TAFI-KO ${ }^{\mathrm{INH}}$ and FVIII-KO mice compared with their respective $\mathrm{WT}^{\mathrm{INH}+}$ controls (Figure $8 \mathrm{C}$ ). Thus, TAFI deficiency phenocopied the aberrant vascular permeability in FVIII deficiency at W2 after joint bleeding, suggesting that defective TAFI activation in hemophilia is responsible for the transient vascular barrier dysfunction in the joint after bleeding.

A stable TAFI mutant corrects bleeding-induced vascular permeability and abnormal vessel enlargement in joints of FVIII-KO mice. To test whether an increased circulating level of TAFI in FVIII-KO mice prevents bleeding-induced vascular abnormalities in the joints, a human TAFI mutant with a 180-fold extended enzymatic half-life (TAFI-CIIYQ; ref. 46) was expressed by hydrodynamic gene delivery (Figure 9A). Prior to initiating treatments after injury, mice were randomized according to the Hct determined 2 days after injury (Figure 9B) to ensure equal bleeding volumes in both groups. The treatment group with TAFI-CIIYQ received a hydrodynamic injection that resulted in a plasma TAFI-CIIYQ level of comparable to that of healthy human plasma 2 days after plasmid DNA injection (Figure 9C). Two weeks after injury, TAFI-CIIYQ reduced vascular leakage in FVIII-KO mice from 1.-9 to 1.3-fold (Figure 9D). Histological examination 2 weeks after injury showed no differences in total CD $31^{+}$vessel counts among untreated versus TAFI-CIIYQ-treated FVIII KO mice (Figure 9E); however, expression of TAFI-CIIYQ did cause a significantly reduced formation of abnormally enlarged vessels ( $\geq 20 \mu \mathrm{m}$ diameter), typical 
A

Anti-FVIII antibody : TAFI-KO INH Anti-FVIII + Anti-TAFI antibody : WT ${ }^{\mathrm{INH}+}$

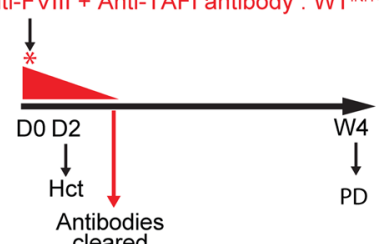

cleared

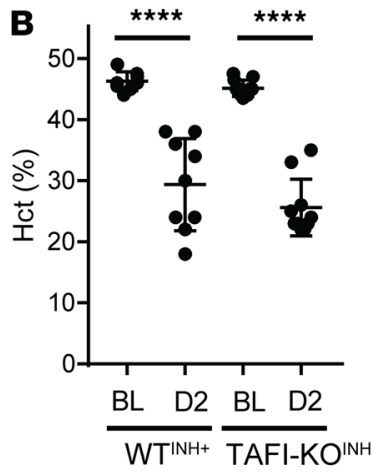

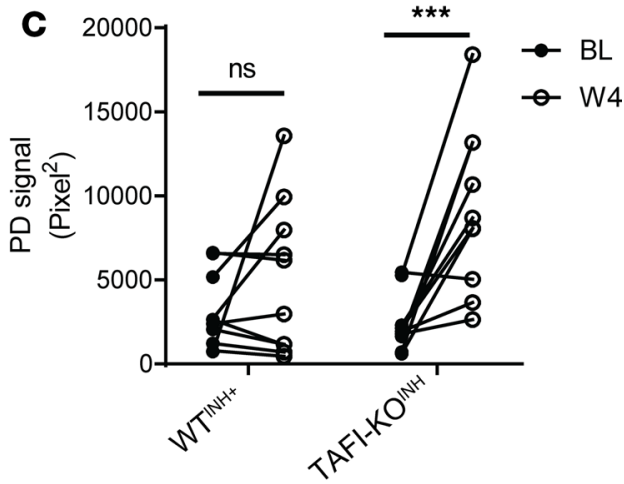
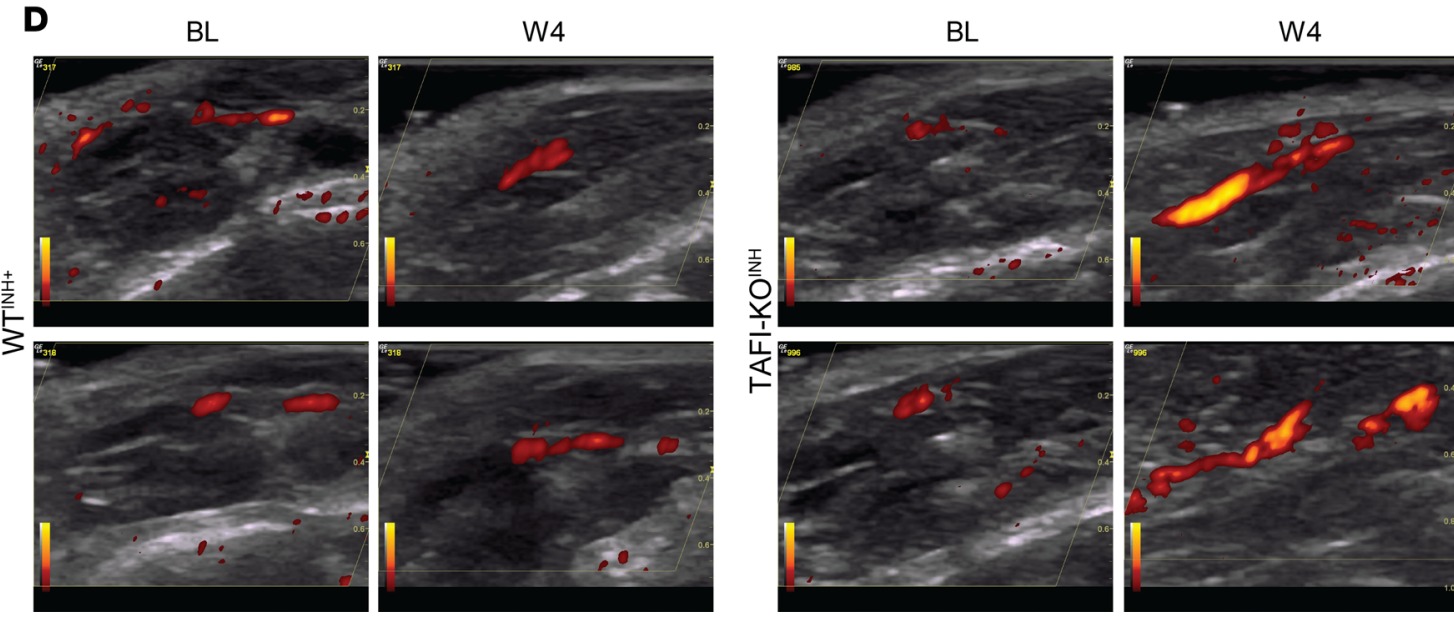

Figure 6. TAFI deficiency in mice increases joint blood flow after bleeding. (A) Schematic of the joint injury model comparing [57BI/6] WT versus TAFIKO mice after hemophilic joint bleeding. Mice were administered anti-FVIII antibody alone (TAFI-KO-inhibitor; TAFI-KO ${ }^{\mathrm{INH}}$ ) or together with an anti-TAFI antibody (WT-inhibitor plus; WT ${ }^{\mathrm{NH}+}$ ). After antibody clearance, vascular blood flow was measured by PD at week 4 (W4) and compared with baseline (BL). Asterisk indicates time of joint injury at day 0 (DO). Hematocrit (Hct) was determined at D2 after injury to assess joint bleeding severity. (B) Joint bleeding after injury in $\mathrm{W}^{\mathrm{INH}+}$ mice $(n=9)$ or TAFI-KO ${ }^{\mathrm{INH}}(n=10)$. Joint bleeding was inferred from a postinjury drop in Hct $(\% ;$ mean \pm SD) at $\mathrm{D} 2$ compared with BL (no-injury reference). Mice with a postinjury Hct below $20 \%$ or above $38 \%$ were excluded to match the bleeding severity in both groups for analyses. (C) Corresponding analysis of knee joint vascularity at BL and W4 after injury by ultrasound power Doppler (PD) signal (pixel2) in WT ${ }^{\mathrm{INH}+}$ and TAFI$\mathrm{KO} \mathrm{INH}^{\mathrm{NH}}$ mice. Each point represents an individual mouse. (D) Representative PD images (2 examples each) obtained from recordings at the medial side of the joint of $\mathrm{WT}^{\mathrm{INH}+}$ or TAFI-KO $\mathrm{INH}^{\mathrm{NH}}$ at BL or W4 after joint injury. The intensity of vascular flow is pseudocolored from low flow (red) to high flow (yellow) as indicated. Original scaled dimensions are $0.86 \mathrm{~cm}(\mathrm{w}) \times 0.63 \mathrm{~cm}(\mathrm{~h})$. Data were analyzed using 1-way ANOVA with Tukey's multiple comparisons test (B) and using Student's 2-tailed, paired $t$ test $(\mathbf{C}) .{ }^{* *} P<0.001 ;{ }^{* * *} P<0.0001$.

for vascular abnormalities in hemophilia after joint bleeding (Figure 9, F and G). Thus, treatment with TAFI-CIIYQ mitigated bleeding-induced vascular defects in hemophilic mouse joints by both preventing aberrant vessel enlargement and stabilizing the vascular barrier.

Inhibition of uPA prevents excessive vascular remodeling in FVIII-KO mice after joint bleeding. To gain insight into whether inhibition of fibrinolysis may contribute to the ability of TAFIa to protect against the maladaptive vascular remodeling response after joint bleeding, the antifibrinolytic drug tranexamic acid (TXA) and the inhibitory anti-uPA antibody mU1 (47) were tested for their potential effects on vascular changes after joint bleeding in FVIII-KO mice. Treatments were initiated 2 days after joint injury to avoid effects on joint bleeding (28) and to ensure equal bleeding volumes (Figure 10A). As a Lys analog, TXA impedes plasminogen binding to partially degraded fibrin and impedes with the fibrin cofactor function in activation of plasminogen. However, treatment with TXA did not affect the neovascular response (Figure 10B), nor did it correct large vessel formation in FVIII-KO mice (Figure 10C). The anti-mouse uPA antibody mU1 that targets uPA's proteolytic activity, but not its binding to uPA receptor (UPAR), also did not affect the neovascular response (Figure 10B); however, it did prevent vessel enlargement to a similar degree as TAFI-CIIYQ (Figure 10, C and D), indicating that TAFI's protective effect may at least in part involve the inhibition of uPA-driven fibrinolysis or pericellular plasmin generation. 

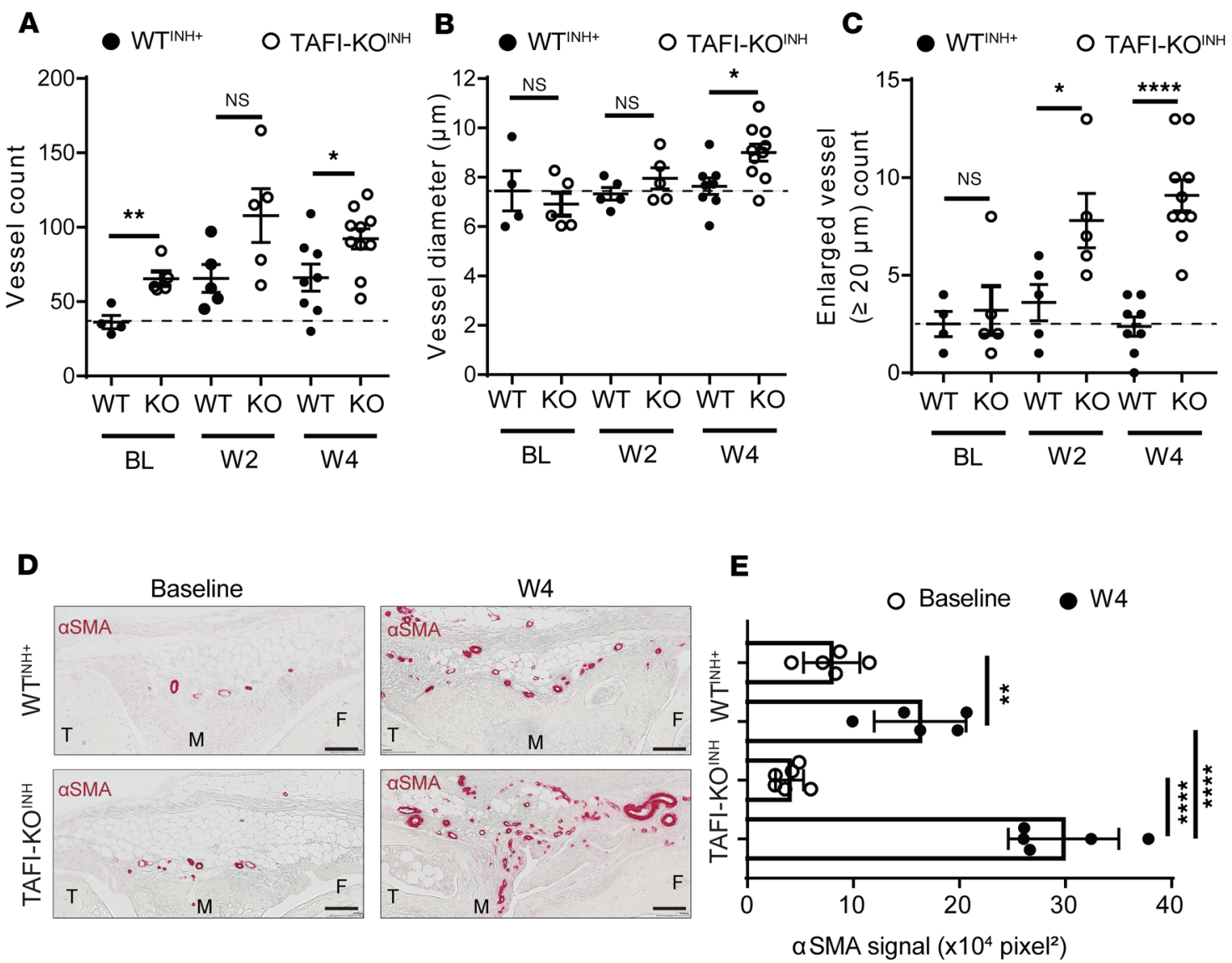

Figure 7. TAFI deficiency in mice underlies excessive vascular remodeling after joint bleeding. Analysis of joint vascularity at baseline (BL; no injury; $n=$ 4-5), 2 weeks (W2; $n=5$ ), and 4 weeks (W4; $n=8-10$ ) after injury based on histology of Safranin 0-fast Green-stained sections of C57BI/6) WT (treated with anti-FVIII antibody and anti-TAFI antibody; $\mathrm{WT}^{\mathrm{INH}+}$ ) or C57BI/6J TAFI-KO (treated with anti-FVIII antibody; TAFI-KO ${ }^{\mathrm{INH}}$ ) mice. (A) Total vessel count, (B) average vessel diameter $(\mu \mathrm{m})$, and (C) vessel count with diameter $\geq 20 \mu \mathrm{m}$. An independent experiment using littermate controls confirmed the observed differences (Supplemental Figure 11). (D) Representative images of perivascular $\alpha$ SMA staining (scale bar: $100 \mu \mathrm{m} ; \mathrm{T}$, tibia; M, meniscus; F, femur) and

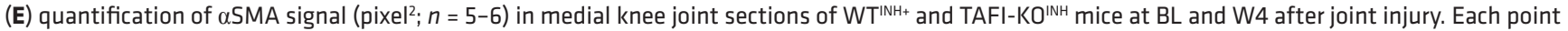
represents an individual mouse. Data are represented as mean \pm SD and were analyzed using Student's 2-tailed, unpaired $t$ test per time point (A-C) and 1-way ANOVA with Tukey's multiple comparisons test $(\mathbf{E}) .{ }^{*} P<0.05 ;{ }^{* *} P<0.01 ;{ }^{* * * *} P<0.0001$.

\section{Discussion}

HA is markedly featured by progressive vascular wall remodeling with vessel enlargement that is associated with acute bleeding events in patients with hemophilia $(9,15)$. While there is consensus that these vascular abnormalities are specific to HA $(9,11)$ and are, thus, caused directly or indirectly by the deficiency of FVIII, the mechanism by which FVIII deficiency results in such pronounced vascular defects after joint bleeding is unknown.

Here, we used mouse models with genetic and transient hemophilia A to discriminate normal responses to joint bleeding from abnormal responses that are caused by FVIII deficiency. Persistent vascular changes were less pronounced in the transient hemophilia A model in WT mice (WT ${ }^{\mathrm{INH}+}$ ) where both FVIII and TAFI were transiently inhibited to cause joint bleeding quantitatively similar to the FVIII-KO mouse. More specifically, WT mice were inherently protected against bleeding-induced excessive vascular remodeling and vascular leakage after the inhibitory antibodies cleared the circulation (4-7 days after injury), indicating that these abnormal vascular changes were associated with FVIII deficiency well after joint bleeding.

Phenocopying of the hemophilia-specific vascular abnormalities in the TAFI-KO ${ }^{\mathrm{INH}}$ mice but not in the $\mathrm{WT}^{\mathrm{INH}+}$ mice pointed toward a prominent role for TAFI deficiency in the development of aberrant vascular permeability and vascular remodeling after joint injury. Both $\mathrm{WT}^{\mathrm{INH}+}$ and TAFI-KO ${ }^{\mathrm{INH}}$ mice have similar joint bleeding volumes and normalized FVIII functions 1 week after injury (28), but they differ in their ability to generate TAFIa when the anti-TAFI antibody has cleared from the circulation. Thus, a prolonged deficiency 
A

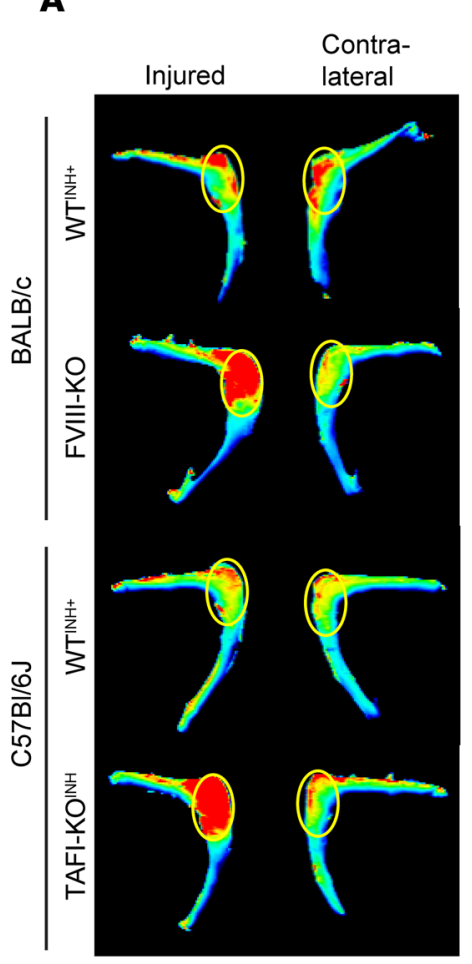

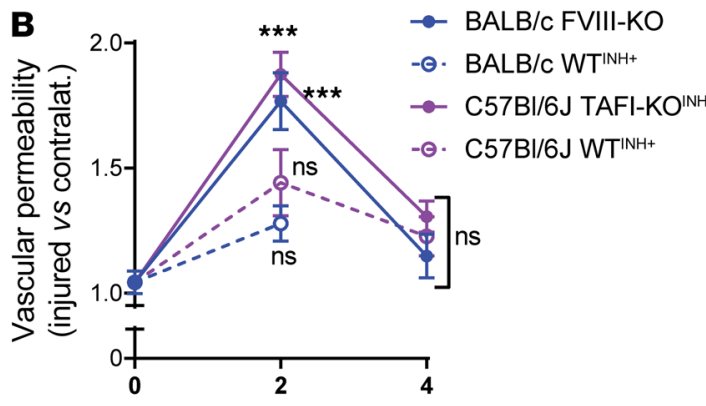

C Time (weeks)

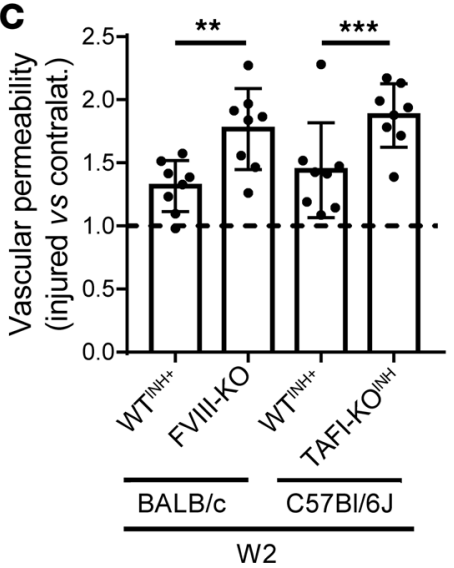

Figure 8. TAFI deficiency phenocopies the vascular permeability in the joints of FVIII-KO mice after bleeding. (A) Representative heatmaps of near-infrared scans showing extravasation of Evans blue-BSA, indicating vascular permeability in the injured versus contralateral (uninjured) medial side of the joints (encircled) of FVIII-KO mice and TAFI$\mathrm{KO}^{\mathrm{INH}}$ and their respective $\mathrm{WT}^{\mathrm{INH}+}$ controls 2 weeks (W2) after joint bleeding. (B) Time course of the vascular permeability (fold increase versus contralateral; mean $\pm \mathrm{SEM}$ ) in the joints of FVIII-KO and TAFI-KOINH mice (full lines) and their respective $\mathrm{WT}^{\mathrm{INH}+}$ controls (same colored, dashed lines) at baseline WO, W2, or W4 after injury $(n=7-8)$. Statistical significance is shown versus baseline. (C) Vascular permeability (fold increase versus contralateral; mean \pm SD) in the joints of FVIII-KO and TAFI-KO ${ }^{\mathrm{INH}}$ mice and their respective $\mathrm{WT}^{\mathrm{INH}+}$ controls 2 weeks after joint injury $(n=8-9)$. Data were analyzed using 1-way ANOVA with Tukey's multiple comparisons test (B and $\mathbf{C}$ ). ${ }^{* *} P<0.01 ;{ }^{* *} P<0.001$ versus baseline control, unless otherwise indicated.

of TAFI, but not of FVIII, was required for the development of vascular abnormalities after joint injury. An indirect mechanism downstream of FVIII deficiency causing vascular abnormalities after joint injury is consistent with the notion that TAFI activation is defective in hemophilia plasma in vitro $(25,27)$ and during hemophilic joint bleeding in vivo (28). Moreover, in vitro data show that activation of TAFI in hemophilia plasma is adequately restored by increasing TAFI zymogen levels due to TAFI's high Km value for activation by thrombin (25). Here, overexpression of a stabilized human TAFI variant, TAFI-CIIYQ (46), prevented bleeding-induced vascular permeability and abnormal vessel enlargement in the joint, providing additional support that defective activation of endogenous TAFI in FVIII-KO mice drives the vascular dysfunction induced by bleeding.

To examine the extent to which TAFI's vascular protective effects in FVIII-KO mice may involve inhibition of plasmin-mediated pericellular proteolysis, the antifibrinolytic agent TXA and the inhibitory mouse uPA antibody, mU1, were tested. Abrogation of uPA's proteolytic activity by mU1 prevented vessel enlargement and mimicked the effects of TAFI-CIIYQ, whereas TXA did not. TXA is currently used successfully in the clinic to reduce excessive bleeding in orthopedic surgery (48), but TXA has no proven effect preventing joint bleeding in patients with hemophilia (49) or in hemophilic mice (28). Protection of the hemophilic joint against excessive vascular remodeling by inhibiting uPA's proteolytic activity with the anti-uPA antibody $\mathrm{mU} 1$, which does not interfere with cellular uPAR binding and signaling functions, is consistent with the reported protective effects of uPA inhibitors in arthritis (50). Increased pericellular plasmin formation due to uPA released by endothelial and inflammatory cells results in facilitation of vascular remodeling via enhanced extracellular matrix degradation and 
A

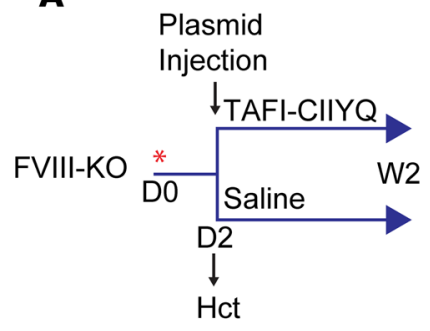

E

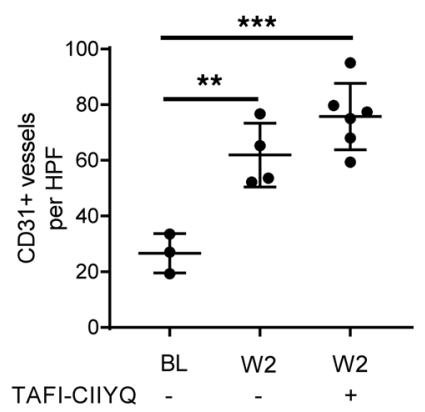

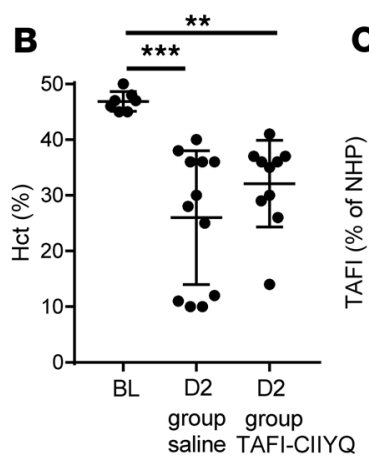

$\mathbf{F}$

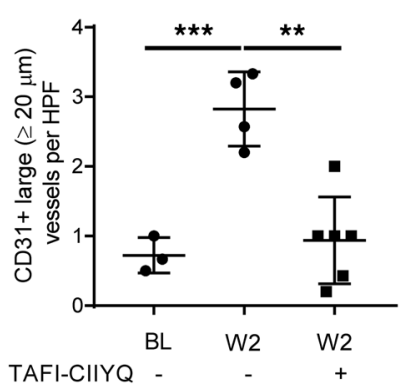

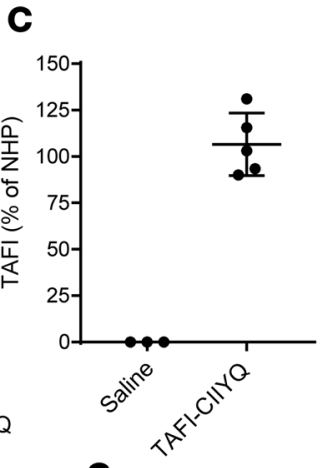
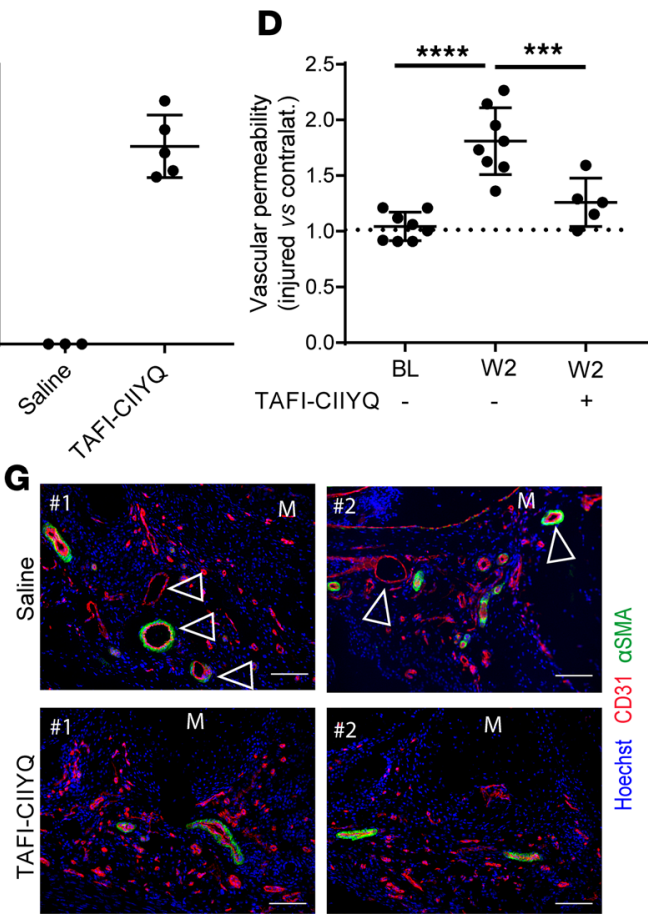

Figure 9. Overexpression of a stabilized TAFI variant normalizes vascular dysfunction in hemophilic mice after joint injury. (A) Experimental schematic. Asterisk indicates time of joint injury in FVIII-KO mice at time point day 0 (DO). Hematocrit (Hct) was determined at D2 after injury to assess joint bleeding severity. Mice were randomized based on their Hct and received either saline or TAFI-CIIYQ-encoding plasmid by hydrodynamic gene delivery. At week 2 (W2) after injury, vascular permeability, total vessel count, and large vessel count were determined. (B) Hct at baseline (BL) and D2 after injury of FVIII-KO treated with saline or TAFI-CIIYQ ( $n=7-10)$. Joint bleeding was inferred from a postinjury drop in Hct compared with BL. (C) In vivo expression levels (\% of normal human plasma [NHP] TAFI level) of circulating TAFI-CIIYQ 2 days after hydrodynamic gene delivery ( $n=6$ ) versus saline injection $(n=3)$. (D) Vascular permeability (fold increase versus contralateral) in the joints of FVIII-KO mice at BL ( $n=8$ ) or W2 after injury treated with saline $(n=8)$ or TAFI-CIIYQ $(n=5)$. (E and F) Total CD31+ vessel count (E) and large CD31+ vessel count $($ with diameter $\geq 20 \mu \mathrm{m})(\mathbf{F})$ in medial knee joint sections per high-power field (HPF) averaged ( $n=4-5 \mathrm{HPF}$ ) per mouse joint at BL or W2 after injury treated with saline or TAFI-CIIYQ ( $n=4-6$ mice). (G) Representative images of medial joint sections (examples from 2 mice, \#1 and \#2) of soft tissue at the anterior meniscus (M) from FVIII-KO mice W2 after injury stained for CD31 (red), $\alpha$ SMA (green), and nuclei (Hoechst, blue) treated with saline (top) and TAFI-CIIYQ (bottom). Open arrowheads indicate CD31+ vessels with a diameter $\geq 20 \mu \mathrm{m}$. Original magnification $20 \times$. Scale bar: $100 \mu \mathrm{m}$. Data are represented as mean \pm SD and were analyzed using 1-way ANOVA with Tukey's multiple comparisons test (B and $\mathbf{D}-\mathbf{F}) .{ }^{*} P<0.01 ;{ }^{* * *} P<0.001 ;{ }^{* * *} P<0.0001$.

augmented vascular cell migration. TAFIa may attenuate uPA-mediated pericellular plasmin formation by cleavage of C-terminal lysines from partially degraded fibrin (51) and plasminogen receptors (35, 52). Some of the protective effects of the anti-uPA antibody may be independent of TAFI, however, as thrombin-mediated inactivation of single chain uPA may also be reduced in hemophilia (53); this cannot be distinguished in the current study. In addition, protection of the joint against excessive vascular remodeling by TAFI is consistent with other protective functions of TAFI in arthritic joints that involve, at least in part, the inactivation of osteopontin and the complement anaphylatoxin C5a (38, 40, 54). Thus, other substrates for TAFIa, left unchecked by the defective activation of TAFI in hemophilia, may also be involved in vascular normalization after joint bleeding, which would extend TAFI's role in hemophilia beyond hemostasis to include inflammation and angiogenesis (28, 55-59).

The development of vascular abnormalities in the joint was also confirmed in aging TAFI-KO mice in 2 independently generated and maintained strains $(44,45)$. In general, mice exhibited spontaneously increased vessel diameters with aging that may be a result of aging-associated chronic and low-grade inflammation. Studies focused on aging-related changes to the synovial vasculature are scarce; however, less regular arrangement of synovial vessels and thickening of the vessel walls with stenosis have been described as degenerative changes with aging in human synovium $(60,61)$. These vascular changes were more pronounced in mice with FVIII or TAFI deficiency, indicating that defective TAFI activation may result in priming the hemophilic joints into a mild proangiogenic state that is propagated abnormally after a hypoxic stimulus, such as caused by bleeding. 

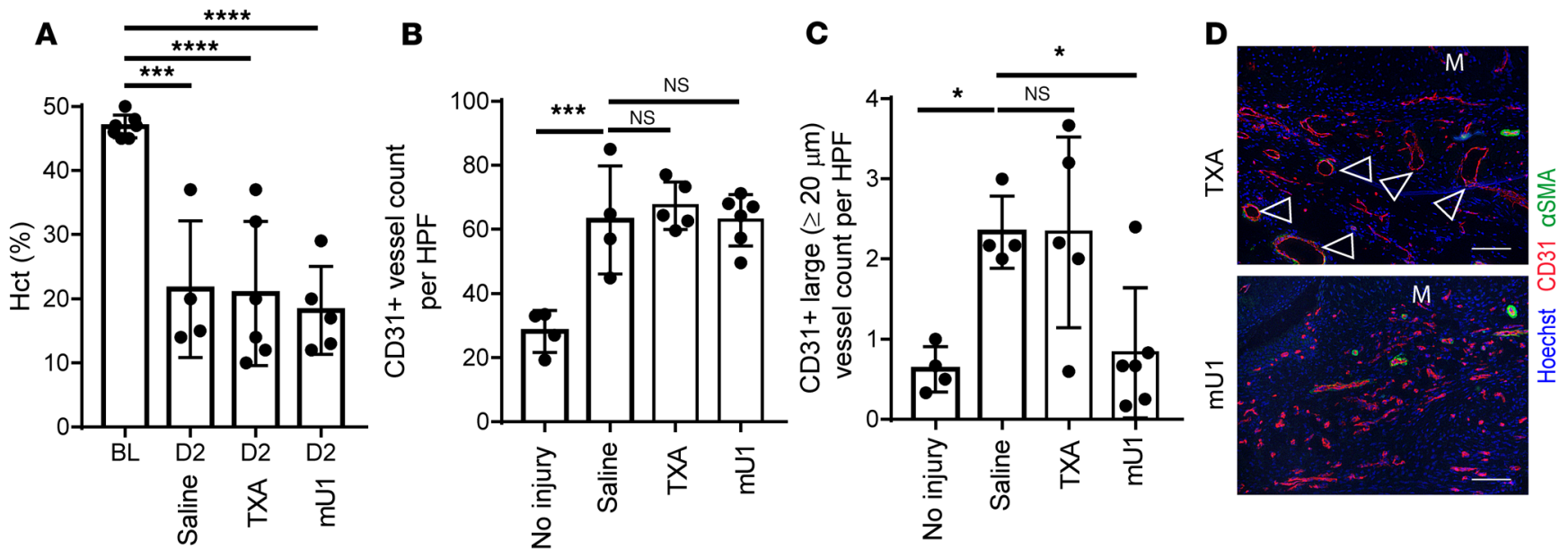

Figure 10. Inhibition of uPA prevents vascular remodeling in hemophilic mice after joint injury. (A) Hct at baseline (BL) and $D 2$ after injury of FVIII-KO treated with saline, TXA, or mU1 $(n=4-6)$. Joint bleeding was inferred from a postinjury drop in Hct compared with BL. (B and C) Total CD31+ vessel count (B) and large CD31+ vessel count (with diameter $\geq 20 \mu \mathrm{m}$ ) (C) in medial knee joint sections per high-power field (HPF) averaged ( $n=4-5 \mathrm{HPF}$ ) per mouse joint at BL or W2 after injury treated with saline or TXA or mU1 $(n=4-6)$. (D) Representative image of medial joint sections of soft tissue at the anterior meniscus (M) from FVIII-KO mice W2 after injury stained for CD31 (red), aSMA (green), and nuclei (Hoechst, blue) treated with TXA (top) and mU1 (bottom). Open arrowheads indicate $C D 31^{+}$vessels with a diameter $\geq 20 \mu \mathrm{m}$. Original magnification $20 \times$. Scale bar: $100 \mu \mathrm{m}$. Data are represented as mean \pm SD and were analyzed using 1-way ANOVA with Tukey's multiple comparisons test (A-C). ${ }^{*} P<0.05 ;{ }^{* *} P<0.001 ;{ }^{* * *} P<0.0001$.

Synovial inflammation, hypertrophy, and neovascular responses to bleeding were also observed in WT mice with transient hemophilia A, albeit milder than in FVIII-KO mice, suggesting that these comprise normal responses to injury and blood in the joint and are part of the repair and regenerative processes that precede healing. Many of these responses were shared between genetic and transient hemophilia mice, but ultimately, the responses in WT mice diverged from the FVIII-KO-like pathology, such that the neovascular response was followed by the eventual pruning and normalization of blood vessel growth. Although proreparative mechanisms are upregulated in FVIII-KO mice after joint bleeding (i.e., increased M2-polarized macrophage response and antiinflammatory cytokines [refs. 15, 62]), the response appears to be maladaptive, as evidenced by differential healing propensities between transient hemophilia A WT and FVIII-KO mice. These different phenotypes observed in FVIII-KO and WT mice point to an important disease-modifying role for the extent of thrombin generation during the healing phase. Although numerous proenzymes are directly or indirectly affected by reduced thrombin generation that may affect outcome, the defective activation of TAFI in FVIII-KO mice, causing a functional TAFI deficiency, plays a major role in aberrant vascular remodeling in HA.

Another difference between WT mice and FVIII-KO or TAFI-KO mice was the aberrant vascular permeability in the joint at W2 after joint bleeding. Vascular leakage was notably less severe in the $\mathrm{WT}^{\mathrm{INH}+}$ mice and TAFI-CIIYQ-expressing FVIII-KO mice compared with FVIII-KO and TAFI-KO ${ }^{\mathrm{INH}}$ mice, indicating that the excessive permeability was due to TAFI deficiency, regardless of whether FVIII was present (TAFI-KO ${ }^{\mathrm{INH}}$ ). The extent to which vascular permeability in the joint parallels or precedes aberrant vascular remodeling is currently not known, but increased synovial blush in the joint is frequently associated with joint bleeding in patients with HA $(16-18,63)$. In addition, the current study demonstrates that aged TAFI-KO mice with spontaneous aberrantly remodeled vessels, as indicated by high PD signals in their joints, were prone to more serious anti-FVIII antibody-induced bleeding compared with mice with normal/low PD signals. Thus, these data provide experimental evidence for the clinical association that abnormal flow patterns due to excessive vascular remodeling and the formation of disorganized fragile blood vessels in the soft tissue are associated with joint bleeding in patients with hemophilia.

In summary, this study identified defective TAFI activation in hemophilia A as an instigator of the development of pathologically enlarged and abnormally remodeled blood vessels in the joint after injury. The notion that TAFI deficiency is sufficient to phenocopy the abnormal vascular remodeling after joint injury even in the presence of FVIII provides the missing mechanistic link between hemophilic joint bleeding and the abnormal vascular leakage and remodeling in HA. These mechanistic insights will help direct targeted studies on the development of vascular normalization approaches in HA and suggest the evaluation 
Table 1. Patient characteristics

\begin{tabular}{|c|c|c|c|c|}
\hline Donor number in Figure 1 & Condition & Tissue & Sex & Age (years) \\
\hline \#1 & Normal & Medial synovium & Male & 36 \\
\hline \#2 & Normal & Medial synovium & Female & 34 \\
\hline \#3 & Normal & Medial synovium & Male & 16 \\
\hline \#4 & Severe hemophilia B & Medial synovium & Male & 55 \\
\hline \#5 & Severe hemophilia A & Medial synovium & Male & 37 \\
\hline \#6 & Severe hemophilia A & Medial synovium & Male & 73 \\
\hline
\end{tabular}

of more aggressive prohemostatic treatment strategies in the period after a joint bleed in patients with hemophilia to promote normal TAFI activation and dampen the dysfunctional vascular response.

\section{Methods}

Animals. FVIII-KO mice on a BALB/c background (64) were a gift of David Lillicrap (Queens University, Ontario, Canada), and WT-BALB/c were obtained from The Scripps Research Institute internal breeding facility. TAFI-KO mice on a C57B1/6J background were a gift of Joost Meijers (Sanquin Research Amsterdam, The Netherlands) $(44,45)$ and were backcrossed 5 generations to C57B1/6J obtained from The Scripps Research Institute internal breeding facility to confirm key findings. A second, independently generated TAFI-KO strain on a C57B1/6J background was maintained at Stanford University School of Medicine (45). Skeletally mature mice (age 12-16 weeks) of both sexes were used for joint injury studies. Moist food was provided on the cage floor, and s.c. injections of buprenorphine $(0.1 \mathrm{mg} / \mathrm{kg}$, Buprenex, Henry Schein) diluted in $400 \mu 1$ sterile saline ( $0.9 \%$, Hospira Inc.) were administered daily after injury to provide pain relief and fluids until the mice were mobile.

Joint injury model. Injury in the mouse right knee joint was induced by subpatellar punctures using a $30 \mathrm{G}$ needle as described (65). Injury-induced bleeding was determined by Hct 2 days after the injury as described (66). A severe injury model was used, consisting of 5 consecutive pokes, to obtain similar bleeding in acquired hemophilia WT mice as in FVIII-KO mice. A very mild injury consisting of a single poke was used to examine the contribution of the baseline vascularity on subsequent joint bleeding.

Animal treatments. Two hours before joint injury, mice were injected retro-orbitally with the inhibitory anti-FVIII antibody (0.25 mg/kg, \#GMA-8015, clone 4A4, Green Mountain Antibodies), GMA-8015 (0.25 $\mathrm{mg} / \mathrm{kg}$, Green Mountain Antibodies) (67, 68), and/or the inhibitory anti-TAFI antibody (7.5 mg/kg, clone MA-RT36A3F5, provided by Paul Declerck, University of Leuven, Belgium [refs. 28, 69]), MA-RT36A3F5 $(28,69)$, which destabilizes TAFIa in sterile saline $(0.9 \%$, Hospira Inc.) to disrupt joint hemostasis. Therapeutic application of TAFI was achieved by hydrodynamic gene delivery of a human TAFI mutant, TAFI-CIIYQ, with an 180-fold extended activity of TAFIa (46). The DNA encoding for TAFI-CIIYQ was inserted in the pLIVE vector (Mirus Bio), and a volume of $10 \%$ of the mouse body weight containing $50 \mu \mathrm{g}$ plasmid DNA in sterile saline $(0.9 \%$, Hospira Inc.) was injected in the tail vein within 5 seconds. In vivo expression of TAFI was quantified by an ELISA assay specific to human TAFI (70), with similar reactivity to TAFI-CIIYQ. Treatment with TXA (4-[aminomethyl]cyclohexane-1-carboxylic acid; Acros Organics) was initiated at D2 after injury and given continuously up to 2 weeks in the drinking water at an effective dosage to shut down ex vivo tissue-type plasminogen activator-mediated (tPA-mediated) clot lysis (71). Treatment with an anti-mouse uPA antbody (clone mU1, generated as described [ref 47]), mU1 was similarly initiated at D2 and given twice a week at $60 \mathrm{mg} / \mathrm{kg}$ up to 2 weeks (50).

Pharmacokinetics of the anti-TAFI antibody MA-RT36A3F5. Plasma concentration-time profiles of antimouse TAFI antibody (clone MA-RT36A3F5, provided by Paul Declerck, University of Leuven, Belgium) were determined in TAFI-KO mice after retro-orbital injection at a dosage of $7.5 \mathrm{mg} / \mathrm{kg}$. Plasma samples were prepared by collecting blood from the retro-orbital plexus in 3.8\% sodium citrate (Fisher Scientific) at 1 minute, 1 hour, 24, 48, 120, 168, 288, and 504 hours, followed by subsequent centrifugation at $5000 \mathrm{~g}$ for 10 minutes. MA-RT36A3F5 concentration was determined by ELISA coated with recombinant mouse TAFI (gift from Paul Declerck, University of Leuven, Belgium) and developed with goat anti-mouse IgGHRP (\#31439; Pierce). Endogenous TAFI levels in mice were determined by a sandwich ELISA utilizing MA-RT36A3F5 and MA-RT30D8-HRP (gift from Paul Declerck, University of Leuven, Belgium) (72). 
Histology. Mouse knee joints were fixed in 10\% zinc-buffered formalin (Z-fix, Anatech LTD) for 2 days and decalcified in Shandon TBD-2 Decalcifier (ThermoFisher Scientific) for 48-72 hours. Sagittal sections (4- $\mu \mathrm{m}$ thick; until anterior and posterior horns of the medial meniscus appeared as triangles between the femoral condyle and tibial plateau) were stained with Safranin O-fast green (Safranin O and fast green from Sigma-Aldrich) as described previously (73).

IHC and immunofluorescence. Knee joint sections were deparaffinized, washed, and blocked with Odyssey Blocking Buffer (LI-COR) (supplemented with 1\% BSA). Primary rabbit polyclonal anti- $\alpha$ SMA antibody (1:100; ab5964, Abcam) was applied and incubated overnight at $4^{\circ} \mathrm{C}$, followed by Impress reagents (Vector Laboratories) and development with VectorRed (Vector Laboratories). The $\alpha$ SMA immunosignal was quantified using a Color Threshold macro in ImageJ (NIH) at the anterior and posterior meniscal area at 10× magnification, and signals were represented as the sum of anterior and posterior signals.

For immunofluorescence of clinical synovial samples, deparaffinized and washed sections were incubated with pepsin solution (Digest-All, Invitrogen) for antigen retrieval, followed by incubation with blocking buffer supplemented with $2 \%$ donkey serum (Jackson ImmunoResearch Laboratories). Alternatively, mouse hindlimb samples were frozen and sectioned on cryofilm using a diamond-coated blade (C.L. Sturkey) using the Kawamoto method (74). Sections were fixed in acetone (Fisher Scientific) for 5 minutes, washed, and blocked in blocking buffer supplemented with $2 \%$ donkey serum. Primary goat anti-mouse CD31 (with cross reactivity to human CD31; 1:20; AF3628, R\&D systems) and rabbit anti- $\alpha$ SMA antibody (1:100; ab5964, Abcam) were used and incubated overnight at $4^{\circ} \mathrm{C}$, followed by Alexa Fluor $568 \mathrm{Cy} 3$ donkey anti-goat IgG (\#705-165-147, Jackson ImmunoResearch Laboratories) and Alexa Fluor 488 donkey anti-rabbit IgG (\# 711-545-152, Jackson ImmunoResearch Laboratories).

Histological assessment of vascularity and inflammation. To evaluate synovial and stromal hyperplasia and vascularity, semiquantitative scoring was performed on Safranin O-fast green-stained joint sections using Valentino (scores 0-9), and Krenn (scores 0-3) scoring systems for the evaluation of synovial and stromal hyperplasia, respectively $(75,76)$. Vascularity was determined as total vessel count per joint, including all synovial and stromal tissue between femoral and tibial growth plates on Safranin O-fast green-stained sections or analyzed on 4-5 high-power fields (HPF) at 20× magnitude on sections stained for CD31 by immunofluorescence. Individual vessel diameters were measured at 40-fold magnification (Safranin O-fast green staining on which only blood vessels with a distinguishable vessel wall and lumen or deduced by the presence of RBCs were considered) or at 20-fold magnification (aided by immunofluorescent staining of CD31 including capillaries with no detectable lumen). Vessel diameters were measured in increments of $5 \mu \mathrm{m}$ by rounding down (e.g., diameters between $5-9 \mu \mathrm{m}$ were considered as $5 \mu \mathrm{m})$. For elliptical vessels, the larger diameter was recorded unless it was equal to or exceeded the smaller diameter by 2.5 -fold. Counting was performed randomized and blinded.

Joint blood flow analysis by ultrasound PD. Joint blood flow was studied using high-resolution musculoskeletal ultrasound (MSKUS) with the GE Logiq E model with gray scale (B-mode) and PD, using transducer frequencies of $8-16 \mathrm{MHz}$ as described previously $(9,15)$. Experimenter was blinded to the mouse identities. Quantification of PD signal was performed using a macro for Color Thresholding in ImageJ.

Vascular permeability assay. Assessment of vascular permeability by means of extravasation of albumin-bound Evans blue dye Evans blue (Sigma-Aldrich) in the mouse knee joints after joint bleeding was performed as described previously (15). Baseline and injured FVIII-deficient mice were injected i.v. with $5 \mu \mathrm{l} / \mathrm{g}$ $0.1 \%$ Evans blue containing $0.8 \%$ (w/v) BSA (Sigma-Aldrich) in sterile PBS. Two hours later, transcardial perfusion was performed at a flow rate of $56 \mathrm{ml} /$ minute for 4 minutes to ensure adequate hindlimb perfusion, and extravasation of Evans blue was quantified on the medial and lateral sides of the harvested knee joints, positioned on a $1 \mathrm{~mm}$-thick glass slide, at $700 \mathrm{~nm}$ using an Odyssey near-infrared imaging system (4 mm offset; laser intensity 2.0; LI-COR). Medial and lateral readings were combined to give total raw fluorescence intensity (RFI) and were expressed as the ratio of right (injured joint) to left (uninjured joint) RFI.

Statistics. The following tests (2-tailed Mann-Whitney $U$ test, Student's unpaired $t$ test, 1-way ANOVA with Tukey's multiple comparison, and Kruskal-Wallis with Dunn's multiple comparisons test) as specified in the figure legends were used to determine statistical significance. Correlations were analyzed using the Pearson correlation test. A $P$ value of $<0.05$ was considered statistically significant and was calculated using GraphPad Prism (San Diego, CA). Data are expressed as mean \pm SD unless noted otherwise.

Study approval. The harvesting of human synovial tissues at the time of total knee replacement surgery was approved by the Scripps Human Subjects Committee and the University of California (UCSD, San Diego, CA) Human Research Protection Program (HRPP). Subjects provided informed consent prior to 
their participation in the study. Subject characteristics are summarized in Table 1. All animal protocols were approved by the IACUC of The Scripps Research Institute.

\section{Author contributions}

TW designed and performed the research, analyzed and interpreted the data, performed statistical analysis, and wrote the manuscript; TY, EJC, JYZ, BW, MO, RA, and YM conducted experiments; JM and NB provided unique mice and reagents; AVD and ML provided scientific and experimental guidance; LOM conceived and designed the study, provided project oversight, experimental guidance, and wrote the manuscript; and all authors read and approved the final manuscript.

\section{Acknowledgments}

FVIII-KO and TAFI-KO mice were made available by David Lillicrap (Queens University, Ontario, Canada) and Joost CM Meijers (Sanquin Research Amsterdam, The Netherlands), respectively. The anti-mouse TAFI antibody (MA-RT36A3F5) was made available by Paul J. Declerck (University of Leuven, Leuven, Belgium). We thank James Luck from LA Ortho and Scott T. Ball from UCSD for sample collection during joint replacement surgery. This study was funded by a National Hemophilia Foundation (NHF) Judith Graham Pool Research Fellowship (TW and EJC), an American Heart Association Western States Postdoctoral Fellowship (TW), The Danish Medical Research Council, the Novo Nordisk Foundation and the Danish Cancer Society (NB), a National Hemophilia Foundation Career Development Award (AVD), and NIH grants AG056144 and AG059418 (ML), and HL142975, HL104165, and HL130678 (LOM).

Address correspondence to: Laurent O. Mosnier, Dept. Mol. Med. (IMM-315), The Scripps Research Institute, 10550 North Torrey Pines Road, La Jolla, CA 92037, USA. Phone: 858.784.2227; Email: 1mosnier@scripps.edu.

1. Manco-Johnson MJ, et al. Prophylaxis versus episodic treatment to prevent joint disease in boys with severe hemophilia. $N E n g l$ J Med. 2007;357(6):535-544.

2. Oldenburg J. Optimal treatment strategies for hemophilia: achievements and limitations of current prophylactic regimens. Blood. 2015;125(13):2038-2044.

3. Olivieri M, Kurnik K, Pfluger T, Bidlingmaier C. Identification and long-term observation of early joint damage by magnetic resonance imaging in clinically asymptomatic joints in patients with haemophilia A or B despite prophylaxis. Haemophilia. 2012;18(3):369-374

4. Wyseure T, Mosnier LO, von Drygalski A. Advances and challenges in hemophilic arthropathy. Semin Hematol. 2016;53(1):10-19.

5. Jackson SC, et al. Prophylaxis in older Canadian adults with hemophilia A: lessons and more questions. BMC Hematol. 2015;15:4.

6. Aznar JA, et al. Haemophilia in Spain. Haemophilia. 2009;15(3):665-675.

7. Schramm W, et al. Haemophilia care in Europe: the ESCHQoL study. Haemophilia. 2012;18(5):729-737.

8. Mulder K, Llinás A. The target joint. Haemophilia. 2004;10 Suppl 4:152-156.

9. Bhat V, et al. Vascular remodeling underlies rebleeding in hemophilic arthropathy. Am J Hematol. 2015;90(11):1027-1035.

10. Kidder W, Chang EY, M Moran C, Rose SC, von Drygalski A. Persistent Vascular Remodeling and Leakiness are Important Components of the Pathobiology of Re-bleeding in Hemophilic Joints: Two Informative Cases. Microcirculation. 2016;23(5):373-378.

11. Melchiorre D, et al. Ultrasound detects joint damage and bleeding in haemophilic arthropathy: a proposal of a score. Haemophilia. 2011;17(1):112-117.

12. Garge S, et al. Role of endovascular embolization in treatment of acute bleeding complications in haemophilia patients. $B r J$ Radiol. 2016;89(1064):20151064.

13. Kolber MK, Shukla PA, Kumar A, Zybulewski A, Markowitz T, Silberzweig JE. Endovascular Management of Recurrent Spontaneous Hemarthrosis After Arthroplasty. Cardiovasc Intervent Radiol. 2017;40(2):216-222.

14. Kim MJ, Oh JY, Park YS. Availability of angiography and therapeutic embolization for the treatment of acute bleeding in patients with hemophilia. Int J Hematol. 2017;106(6):787-793.

15. Cooke EJ, et al. Vascular Permeability and Remodelling Coincide with Inflammatory and Reparative Processes after Joint Bleeding in Factor VIII-Deficient Mice. Thromb Haemost. 2018;118(6):1036-1047.

16. Galli E, Baques A, Moretti N, Candela M, Caviglia H. Hemophilic chronic synovitis: therapy of hemarthrosis using endovascular embolization of knee and elbow arteries. Cardiovasc Intervent Radiol. 2013;36(4):964-969.

17. Mauser-Bunschoten EP, Zijl JA, Mali W, van Rinsum AC, van den Berg HM, Roosendaal G. Successful treatment of severe bleeding in hemophilic target joints by selective angiographic embolization. Blood. 2005;105(7):2654-2657.

18. Saris DB, van Rinsum AC, Dhert WJ, Roosendaal G, Mali WP. Periarticular aneurysm formation in haemophilia. Lancet. 1997;349(9054):766-768.

19. Wen FQ, Jabbar AA, Chen YX, Kazarian T, Patel DA, Valentino LA. c-myc proto-oncogene expression in hemophilic synovitis: in vitro studies of the effects of iron and ceramide. Blood. 2002;100(3):912-916.

20. Hakobyan N, Kazarian T, Jabbar AA, Jabbar KJ, Valentino LA. Pathobiology of hemophilic synovitis I: overexpression of 
mdm2 oncogene. Blood. 2004;104(7):2060-2064.

21. Øvlisen K, Kristensen AT, Jensen AL, Tranholm M. IL-1 beta, IL-6, KC and MCP-1 are elevated in synovial fluid from haemophilic mice with experimentally induced haemarthrosis. Haemophilia. 2009;15(3):802-810.

22. Acharya SS, Kaplan RN, Macdonald D, Fabiyi OT, DiMichele D, Lyden D. Neoangiogenesis contributes to the development of hemophilic synovitis. Blood. 2011;117(8):2484-2493.

23. Boffa MB, Wang W, Bajzar L, Nesheim ME. Plasma and recombinant thrombin-activable fibrinolysis inhibitor (TAFI) and activated TAFI compared with respect to glycosylation, thrombin/thrombomodulin-dependent activation, thermal stability, and enzymatic properties. J Biol Chem. 1998;273(4):2127-2135.

24. Bajzar L, Morser J, Nesheim M. TAFI, or plasma procarboxypeptidase B, couples the coagulation and fibrinolytic cascades through the thrombin-thrombomodulin complex. J Biol Chem. 1996;271(28):16603-16608.

25. Mosnier LO, Lisman T, van den Berg HM, Nieuwenhuis HK, Meijers JC, Bouma BN. The defective down regulation of fibrinolysis in haemophilia A can be restored by increasing the TAFI plasma concentration. Thromb Haemost. 2001;86(4):1035-1039

26. Foley JH, Nesheim ME. Soluble thrombomodulin partially corrects the premature lysis defect in FVIII-deficient plasma by stimulating the activation of thrombin activatable fibrinolysis inhibitor. J Thromb Haemost. 2009;7(3):453-459.

27. Foley JH, Nesheim ME, Rivard GE, Brummel-Ziedins KE. Thrombin activatable fibrinolysis inhibitor activation and bleeding in haemophilia A. Haemophilia. 2012;18(3):e316-e322.

28. Wyseure T, et al. Defective TAFI activation in hemophilia A mice is a major contributor to joint bleeding. Blood. 2018;132(15):1593-1603.

29. Eaton DL, Malloy BE, Tsai SP, Henzel W, Drayna D. Isolation, molecular cloning, and partial characterization of a novel carboxypeptidase B from human plasma. J Biol Chem. 1991;266(32):21833-21838.

30. Tsai SP, Drayna D. The gene encoding human plasma carboxypeptidase B (CPB2) resides on chromosome 13. Genomics. 1992;14(2):549-550.

31. Bajzar L, Manuel R, Nesheim ME. Purification and characterization of TAFI, a thrombin-activable fibrinolysis inhibitor. $J$ Biol Chem. 1995;270(24):14477-14484

32. Redlitz A, Nicolini FA, Malycky JL, Topol EJ, Plow EF. Inducible carboxypeptidase activity. A role in clot lysis in vivo. Circulation. 1996;93(7):1328-1330.

33. Guimarães AH, Laurens N, Weijers EM, Koolwijk P, van Hinsbergh VW, Rijken DC. TAFI and pancreatic carboxypeptidase B modulate in vitro capillary tube formation by human microvascular endothelial cells. Arterioscler Thromb Vasc Biol. 2007;27(10):2157-2162.

34. Bazzi ZA, Balun J, Cavallo-Medved D, Porter LA, Boffa MB. Activated thrombin-activatable fibrinolysis inhibitor attenuates the angiogenic potential of endothelial cells: potential relevance to the breast tumour microenvironment. Clin Exp Metastasis. 2017;34(2):155-169.

35. Bazzi ZA, et al. Activated thrombin-activatable fibrinolysis inhibitor (TAFIa) attenuates breast cancer cell metastatic behaviors through inhibition of plasminogen activation and extracellular proteolysis. BMC Cancer. 2016;16:328.

36. Schultz G, et al. Enhanced abdominal aortic aneurysm formation in thrombin-activatable procarboxypeptidase B-deficient mice Arterioscler Thromb Vasc Biol. 2010;30(7):1363-1370.

37. Lepus CM, et al. Brief report: carboxypeptidase B serves as a protective mediator in osteoarthritis. Arthritis Rheumatol. 2014;66(1):101-106.

38.Leung LL, Myles T, Nishimura T, Song JJ, and Robinson WH. Molecular immunology. England; 2008(16):4080-3.

39. Sharif SA, et al. Thrombin-activatable carboxypeptidase B cleavage of osteopontin regulates neutrophil survival and synoviocyte binding in rheumatoid arthritis. Arthritis Rheum. 2009;60(10):2902-2912.

40. Song JJ, et al. Plasma carboxypeptidase B downregulates inflammatory responses in autoimmune arthritis. J Clin Invest. 2011;121(9):3517-3527.

41. Lozier JN, Nichols TC. Animal models of hemophilia and related bleeding disorders. Semin Hematol. 2013;50(2):175-184

42. Bi L, et al. Further characterization of factor VIII-deficient mice created by gene targeting: RNA and protein studies. Blood. 1996;88(9):3446-3450.

43. Kelly S, et al. Angiogenic gene expression and vascular density are reflected in ultrasonographic features of synovitis in early Rheumatoid Arthritis: an observational study. Arthritis Res Ther. 2015;17:58.

44. te Velde EA, et al. Impaired healing of cutaneous wounds and colonic anastomoses in mice lacking thrombin-activatable fibrinolysis inhibitor. J Thromb Haemost. 2003;1(10):2087-2096.

45. Nagashima M, et al. Thrombin-activatable fibrinolysis inhibitor (TAFI) deficiency is compatible with murine life. J Clin Invest. 2002;109(1):101-110.

46. Ceresa E, Van de Borne K, Peeters M, Lijnen HR, Declerck PJ, Gils A. Generation of a stable activated thrombin activable fibrinolysis inhibitor variant. J Biol Chem. 2006;281(23):15878-15883.

47. Lund IK, et al. Antibody-mediated targeting of the urokinase-type plasminogen activator proteolytic function neutralizes fibrinolysis in vivo. J Biol Chem. 2008;283(47):32506-32515.

48. Stowers MDJ, Aoina J, Vane A, Poutawera V, Hill AG, Munro JT. Tranexamic Acid in Knee Surgery Study-A Multicentered, Randomized, Controlled Trial. J Arthroplasty. 2017;32(11):3379-3384

49. Srivastava A, et al. Guidelines for the management of hemophilia. Haemophilia. 2013;19(1):e1-47.

50. Almholt K, et al. Antibody-Mediated Neutralization of uPA Proteolytic Function Reduces Disease Progression in Mouse Arthritis Models. J Immunol. 2018;200(3):957-965.

51. Wang W, Boffa MB, Bajzar L, Walker JB, Nesheim ME. A study of the mechanism of inhibition of fibrinolysis by activated thrombin-activable fibrinolysis inhibitor. J Biol Chem. 1998;273(42):27176-27181.

52. Herren T, Swaisgood C, Plow EF. Regulation of plasminogen receptors. Front Biosci. 2003;8:d1-d8.

53. Braat EA, Jie AF, Ronday HK, Beekman B, Rijken DC. Urokinase-mediated fibrinolysis in the synovial fluid of rheumatoid arthritis patients may be affected by the inactivation of single chain urokinase type plasminogen activator by thrombin. Ann Rheum Dis. 2000;59(4):315-318.

54. So AK, et al. Arthritis is linked to local and systemic activation of coagulation and fibrinolysis pathways. J Thromb Haemost. 
2003;1(12):2510-2515.

55. Colucci M, Semeraro N. Thrombin activatable fibrinolysis inhibitor: at the nexus of fibrinolysis and inflammation. Thromb Res. 2012;129(3):314-319.

56. Fujiwara A, et al. Role of thrombin-activatable fibrinolysis inhibitor in allergic bronchial asthma. Lung. 2012;190(2):189-198.

57. Leung LL, Nishimura T, Myles T. Regulation of tissue inflammation by thrombin-activatable carboxypeptidase B (or TAFI) Adv Exp Med Biol. 2008;632:61-69.

58. Rooth E, et al. Thrombin activatable fibrinolysis inhibitor and its relationship to fibrinolysis and inflammation during the acute and convalescent phase of ischemic stroke. Blood Coagul Fibrinolysis. 2007;18(4):365-370.

59. Myles T, et al. Thrombin activatable fibrinolysis inhibitor, a potential regulator of vascular inflammation. J Biol Chem. 2003;278(51):51059-51067.

60. Pasquali-Ronchetti I, et al. Aging of the human synovium: an in vivo and ex vivo morphological study. Semin Arthritis Rheum. 1992;21(6):400-414.

61. Elmore SM, Malmgren RA, Sokoloff L. Sclerosis of Synovial Blood Vessels. Journal of Bone and Joint Surgery-American Volume. $1963 ; 45(2): 318-26$.

62. Nieuwenhuizen L, et al. Hemarthrosis in hemophilic mice results in alterations in M1-M2 monocyte/macrophage polarization. Thromb Res. 2014;133(3):390-395.

63. Kidder W, Nguyen S, Larios J, Bergstrom J, Ceponis A, von Drygalski A. Point-of-care musculoskeletal ultrasound is critical for the diagnosis of hemarthroses, inflammation and soft tissue abnormalities in adult patients with painful haemophilic arthropathy. Haemophilia. 2015;21(4):530-537.

64. Brown BD, et al. Factors influencing therapeutic efficacy and the host immune response to helper-dependent adenoviral gene therapy in hemophilia A mice. J Thromb Haemost. 2004;2(1):111-118.

65. Hakobyan N, Enockson C, Cole AA, Sumner DR, Valentino LA. Experimental haemophilic arthropathy in a mouse model of a massive haemarthrosis: gross, radiological and histological changes. Haemophilia. 2008;14(4):804-809.

66. von Drygalski A, Furlan-Freguia C, Ruf W, Griffin JH, Mosnier LO. Organ-specific protection against lipopolysaccharide-induced vascular leak is dependent on the endothelial protein C receptor. Arterioscler Thromb Vasc Biol. 2013;33(4):769-776.

67. Bhat V, von Drygalski A, Gale AJ, Griffin JH, Mosnier LO. Improved coagulation and haemostasis in haemophilia with inhibitors by combinations of superFactor Va and Factor VIIa. Thromb Haemost. 2016;115(3):551-561.

68. Summers RJ, et al. Factor VIII A3 domain substitution N1922S results in hemophilia A due to domain-specific misfolding and hyposecretion of functional protein. Blood. 2011;117(11):3190-3198.

69. Hillmayer K, Vancraenenbroeck R, De Maeyer M, Compernolle G, Declerck PJ, Gils A. Discovery of novel mechanisms and molecular targets for the inhibition of activated thrombin activatable fibrinolysis inhibitor. J Thromb Haemost. 2008;6(11):1892-1899.

70. Mosnier LO, von dem Borne PA, Meijers JC, Bouma BN. Plasma TAFI levels influence the clot lysis time in healthy individuals in the presence of an intact intrinsic pathway of coagulation. Thromb Haemost. 1998;80(5):829-835.

71. Isermann B, et al. The thrombomodulin-protein $\mathrm{C}$ system is essential for the maintenance of pregnancy. Nat Med. 2003;9(3):331-337.

72. Hillmayer K, et al. Development of sandwich-type ELISAs for the quantification of rat and murine thrombin activatable fibrinolysis inhibitor in plasma. J Thromb Haemost. 2008;6(1):132-138.

73. Caramés B, Hasegawa A, Taniguchi N, Miyaki S, Blanco FJ, Lotz M. Autophagy activation by rapamycin reduces severity of experimental osteoarthritis. Ann Rheum Dis. 2012;71(4):575-581.

74. Kawamoto T, Kawamoto K. Preparation of thin frozen sections from nonfixed and undecalcified hard tissues using Kawamot's film method (2012). Methods Mol Biol. 2014;1130:149-164.

75. Valentino LA, Hakobyan N. Histological changes in murine haemophilic synovitis: a quantitative grading system to assess blood-induced synovitis. Haemophilia. 2006;12(6):654-662.

76. Krenn V, Morawietz L, Häupl T, Neidel J, Petersen I, König A. Grading of chronic synovitis--a histopathological grading system for molecular and diagnostic pathology. Pathol Res Pract. 2002;198(5):317-325. 